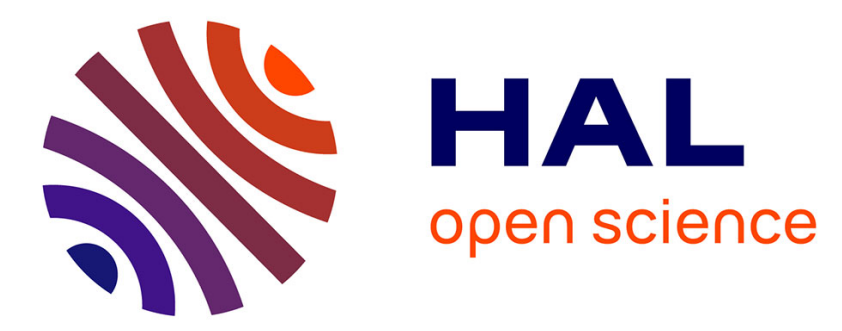

\title{
Intertemporal equilibrium with financial asset and physical capital
}

Cuong Le Van, Ngoc-Sang Pham

\section{To cite this version:}

Cuong Le Van, Ngoc-Sang Pham. Intertemporal equilibrium with financial asset and physical capital. 2014. halshs-01147470v2

\section{HAL Id: halshs-01147470 \\ https://shs.hal.science/halshs-01147470v2}

Submitted on 19 May 2015

HAL is a multi-disciplinary open access archive for the deposit and dissemination of scientific research documents, whether they are published or not. The documents may come from teaching and research institutions in France or abroad, or from public or private research centers.
L'archive ouverte pluridisciplinaire HAL, est destinée au dépôt et à la diffusion de documents scientifiques de niveau recherche, publiés ou non, émanant des établissements d'enseignement et de recherche français ou étrangers, des laboratoires publics ou privés. 


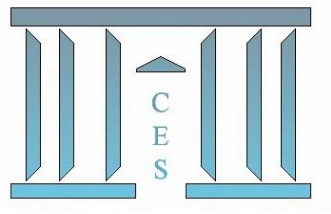

Intertemporal equilibrium with financial asset and physical capital

Cuong LE VAN, Ngoc-Sang PHAM

$$
\text { 2014.85R }
$$

Version révisée

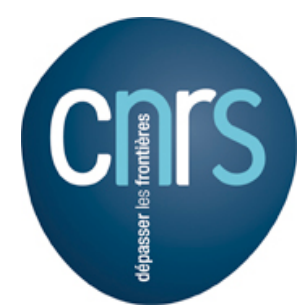




\title{
Intertemporal equilibrium with financial asset and physical capital*
}

\author{
Cuong Le $\operatorname{Van}^{\dagger}$ \\ CNRS, Paris School of Economics, IPAG Business School, VCREME \\ Ngoc-Sang Pham \\ EPEE, University of Evry
}

February 21, 2015

\begin{abstract}
We build an infinite-horizon dynamic deterministic general equilibrium model with imperfect markets (because of borrowing constraints), in which heterogeneous agents invest in capital or/and financial asset, and consume. There is a representative firm who maximizes its profit. Firstly, the existence of intertemporal equilibrium is proved even if aggregate capital is not uniformly bounded. Secondly, we study the interaction between the financial market and the productive sector. We also explore the nature of physical capital bubble and financial asset bubble as well.
\end{abstract}

Keywords: Infinite horizon, intertemporal equilibrium, financial friction, productivity, efficiency, fluctuation, bubbles.

JEL Classifications: C62, D31, D91, G10, E44.

\section{Introduction}

The recent financial crisis requires us to reconsider the role of the financial market on aggregate economic activities. The financial market has been considered as one of the main causes of recession or/and fluctuation. But, does the financial market

*This research was completed with the support of the Novo Tempus research grant, ANR-12BSH1-0007, Program BSH1-2012, and Labex MME-DII. The authors thank to an associate editor and two anonymous referees for their comments and suggestions.

$\dagger$ Email: Cuong.Le-Van@univ-paris1.fr, address: Maisons des Sciences Economiques, 106-112 Boulevard de l'Hopital, 75013 Paris, France.

${ }_{\ddagger}^{\ddagger}$ Corresponding author, email: pns.pham@gmail.com, address: Office 304, Building Ile de France, 4 boulevard Franois Mitterrand, 91025 Evry Cedex, France. 
always cause an recession in the productive sector? What is the role of the financial market on the productive sector? What is the nature of bubbles?

To answer these questions, our approach is to construct a dynamic deterministic general equilibrium model with heterogeneous agents, capital accumulation, and imperfect financial market. In our model, consumers differ in discount factors, reward functions and initial wealths. ${ }^{1}$ Heterogeneous consumers invest, borrow, and consume. They have two choices to invest: in productive sector and in financial sector. At date $t$, if one invests in the physical capital, he (or she) will receive a return that depends on the marginal productivity of the economy at next date. In the financial market, if he (or she) buys one unit of financial asset at date $t$, he (or she) will be able to resell this asset and also receive $\xi_{t+1}$ units of consumption good as dividend. ${ }^{2}$ When agents want to borrow, they are required to hold some amounts of physical capital as collateral. The market value of collateral must be greater than the value of debt. Because of this constraint, the financial market is imperfect.

The first contribution of our paper concerns the existence of intertemporal equilibrium. Becker, Boyd III, and Foias (1991) demonstrated the existence of intertemporal equilibrium under borrowing constraints with inelastic labor supply. Kubler and Schmedders (2003) constructed and proved the existence of Markov equilibrium in an infinite-horizon asset pricing model with incomplete markets and collateral constraints, but without capital accumulation. Such a Markov equilibrium was also proved to be competitive equilibrium. Becker, Bosi, Le Van, and Seegmuller (2014) proved the existence of a Ramsey equilibrium with endogenous labor supply and borrowing constraint on physical capital; however, they only considered an implicit financial market and assumed that no one can borrow. In these papers, they needed some assumptions (about endowments as in Kubler and Schmedders (2003), and about production function as in Becker, Boyd III, and Foias (1991), Becker, Bosi, Le Van, and Seegmuller (2014)) to ensure that aggregate capital and consumption stocks are uniformly bounded. Here we allow growth for the physical quantities (consumption, capital stocks, outputs). Our framework is rich enough to cover both productive sector and imperfect financial market. ${ }^{3}$ Moreover, in our proof of the existence of an intertemporal equilibrium, we allow non-stationary and even linear production functions and do not need that aggregate capital and consumption stocks be uniformly bounded. We firstly prove that there exists an equilibrium for each $T$-truncated economy. We then obtain a sequence of equilibria (indexed by $T$ ) which will be proved to have a limit for the product topology. Last, we prove that such limit is an intertemporal equilibrium.

Analyzing the relationship between the financial market and the productive sector is our second contribution. We explore three important points.

The first one concerns the recession in the productive sector by which we mean a situation where no one invests in this sector. Although there are many sources for

\footnotetext{
${ }^{1} \mathrm{~A}$ detailed survey on the effects of heterogeneity in macroeconomics can be found in Guvenen $(2012)$

${ }^{2}$ This asset may be interpreted as land, or security (Santos and Woodford , 1997), or stock (Kocherlakota , 1992)...

${ }^{3}$ However, for simplicity, we assume exogenous supply of labor.
} 
recession as war, policy shocks, financial shocks..., we focus on productivity of the productive sector. Our finding is summarized as follows.

(i) When the productivity is high enough, the productive sector never falls in recession.

(ii) When the productivity is low, the productive sector will fall in recession at infinitely many dates (not necessary at all dates) because the agents prefer financial assets to physical capital.

(iii) However, at some dates, even when the productivity is low, financial assets may be beneficial to the productive sector by providing financial support for the purchase of the physical capital. Thanks to that, a recession may be avoided.

Moreover, high productivity and good dividends may prevent this sector to collapse, i.e., to converge to zero when time goes to infinity.

The second point concerns fluctuations of the aggregate capital path $\left(K_{t}\right)$. We prove that, under some mild conditions, there exists an infinite sequence of time $\left(t_{n}\right)$ such that $K_{t_{n}}=0$ for every $n$, but $\limsup _{t \rightarrow \infty} K_{t}>0$.

The third point focuses on the efficiency intertemporal equilibrium. An intertemporal equilibrium is called to be efficient if its aggregate capital path is efficient in the sense of Malinvaud (1953). When the production technology is stationary such that $F^{\prime}(\infty)<\delta$ and the financial dividends are bounded from above and away from zero, we prove that every equilibrium is efficient. Our finding is different from Becker, Dubey, and Mitra (2014) where they give an example of inefficient Ramsey equilibrium in a model with only physical capital.

In the last part of the paper, we studies physical and financial bubbles and the connection between these bubbles.

We say that there is a financial asset (resp., physical capital) bubble if the market price of the financial asset (resp., physical capital) is greater than the fundamental value of the financial asset (resp., physical capital). Note that the fundamental values of both physical capital and financial asset are endogenously defined and depends on the structure of these assets.

Our definition of financial bubble is in line with Kocherlakota (1992), Santos and Woodford (1997), Huang and Werner (2000), Le Van, Pham, and Vailakis (2014). Different from these papers, we study financial bubble when production is taken into account. We show that when the present value of output is finite, financial bubble is ruled out, ${ }^{4}$ and we also prove that this is only a sufficient condition ruling out financial bubble. Moreover, this is an endogenous condition since the present value of output is endogenously defined. We also give a condition (on exogenous parameters of the economy) which rules financial bubble: the production technology is stationary such that $F^{\prime}(\infty)<\delta$ and the financial dividends are bounded from

\footnotetext{
${ }^{4}$ Our no-bubble result is consistent with the well-known result in Kocherlakota (1992), Santos and Woodford (1997), Huang and Werner (2000) where they proved that there is no financial asset bubble if the fundamental value of the aggregate endowments is finite.
} 
above and away from zero. As discussed above, every equilibrium is efficient under these conditions.

Our finding shows that when the ratios of the financial dividends to the total outputs are bounded away from below then there exists no financial bubble at equilibrium. We then give examples where these ratios tend to zero, and financial bubbles arise.

The concept physical bubble is firstly introduced by Becker, Bosi, Le Van, and Seegmuller (2014) in a model with only physical capital. In their framework physical bubble is ruled out because the technology is stationary and capital returns are bounded from below. Then Bosi, Le Van, and Pham (2014) allowed for nonstationary technologies and found out that physical bubble exists if and only if the sum (over time) of expected capital returns $\left(\rho_{t}\right)$ is finite, i.e., $\sum_{t=1}^{\infty} \rho_{t}<\infty$. In our paper, the presence of financial asset affects the existence of physical bubble. The reason is that the financial asset affects the discount factors of the economy and then the expected capital returns. An interesting point is that when financial dividends $\left(\xi_{t}\right)$ are not too low (in the sense that $\lim \sup \xi_{t}>0$ ) then physical bubble is ruled out.

We also give examples where the technology is not stationary and dividends are low, and there is physical bubble at equilibrium. Interestingly physical and financial bubbles may co-exist at equilibrium.

Other literature: Our paper is related to several strands of research.

(i) The first strand concerns General equilibrium with incomplete markets. An excellent introduction to asset pricing models with incomplete markets and infinite horizon can be found in Magill and Quinzii (2008). On collateral equilibrium, Geanakoplos and Zame (2002) proved the existence of collateral equilibrium in a two-period models that incorporates durables gooods and collateralized securities. By extending Geanakoplos and Zame (2002), Araujo, Pascoa, and Torres-Martinez (2002) proved the existence of equilibrium for an infinite horizon models with collateral requirement on selling financial assets. Pham (2013) proved the existence of collateralized monetary equilibrium in an infinite horizon monetary economy. Note that, in these papers, they did not take into account the role of the productive sector.

(ii) Credit market frictions and aggregate economic activity: Our paper is also related to Kiyotaki and Moore (1997). However, they did not take into account the existence of intertemporal equilibrium. Some other significant researchs (Scheinkman and Weiss (1986), Bernanke, Gertler, and Gilchrist (1999), Matsuyama (2007), Gertler and Kiyotaki (2010), Christiano, Motto, and Rostagno (2010)) explained why credit market frictions can make impact on aggregate econnomic activity. Gabaix (2011) proposes that idiosyncratic firm-level shocks can explain an important part of aggregate movements. Brunnermeier and Sannikov (2014) incorporated financial sector in a macroeconomic model with continuous time. See Brunnermeier, Eisenbach, and Sannikov (2012) for a complete review on macroeconomics with financial frictions.

(iii) On the efficiency of capital paths. Malinvaud (1953) introduced the con- 
cept of efficiency of a capital path and gave a sufficient condition of the efficiency: $\lim _{t \rightarrow \infty} P_{t} K_{t}=0$, where $\left(P_{t}\right)$ is a sequence of competitive prices, $\left(K_{t}\right)$ is the capital path. ${ }^{5}$ Following Malinvaud, Cass (1972) considered capital path which is uniformly bounded away from zero. Under the concavity of the stationary production function and some mild conditions, he proved that a capital path is inefficient if and only if the sum (over time) of future values of a unit of physical capital is finite. Cass and Yaari (1971) gave a necessary and sufficient condition for a consumption plan $(C)$ to be efficient, which can be stated that the inferior limit of differences between the present value of any consumption plan and the plan $(C)$ is negative. Our paper is also related to Becker and Mitra (2012) where they proved that a Ramsey equilibrium is efficient if the most patient household is not credit constrained from some date. Mitra and Ray (2012) studied the efficiency of a capital path with nonconvex production technologies and examined whether the Phelps-Koopmans theorem is valid.

Our finding is different from their result because we introduce another long-lived asset into a standard Ramsey model with heterogeneous agents. Exogenous dividends of this asset play an important role on the efficiency of capital paths. It may make aggregate capital paths efficient. Interestingly, thanks to financial dividends, an efficient capital path may have zero capital stocks at some dates. ${ }^{6}$

The remainder of the paper is organized as follows. Section 2 presents the structure of economy. In Section 3, we discuss about the existence of intertemporal equilibrium. Section 4 studies the interaction between the financial market and the productive sector. The efficiency of intertemporal equilibrium is presented in Section 5. Section 6 gives conditions to have no bubble on both markets. Section 7 concludes. Technical proofs can be found in Appendix.

\section{Model}

The model is an infinite-horizon general equilibrium model without uncertainty and discrete time $t=0, \ldots, \infty$. There are two types of agents: a representative firm without market power and $m$ heterogeneous households. Each household invests in physical asset and/or financial asset, and consumes.

Consumption good: there is a single consumption good. At each period $t$, the price of consumption good is denoted by $p_{t}$ and agent $i$ consumes $c_{i, t}$ units of consumption good.

Physical capital: at time $t$, if agent $i$ buys $k_{i, t+1} \geq 0$ units of new capital, agent $i$ will receive $(1-\delta) k_{i, t+1}$ units of old capital at period $t+1$, after being depreciated ( $\delta$ is the depreciation rate), and $k_{i, t+1}$ units of old capital can be sold at price $r_{t+1}$.

\footnotetext{
${ }^{5}$ See Malinvaud (1953), Lemma 5, page 248.

${ }^{6}$ Another concept of efficiency is constrained efficiency. Constrained inefficiency occurs when there exists a welfare improving feasible redistribution subject to constraints (these constraints depend on models). About the constrained efficiency in general equilibrium models with financial asset and without capital accumulation, see Kehoe and Levine (1993), Alvarez and Jermann (2000), Bloise and Reichlin (2011). About the constrained efficiency in the neoclassical growth model, see Davila, Hong, Krusell, and Rios-Rull (2012).
} 
Financial asset: at period $t$, if agent $i$ invests $a_{i, t}$ units of financial asset with price $q_{t}$, she will receive $\xi_{t+1}$ units of consumption good as dividend and she will be able to resell $a_{i, t}$ units of financial asset with price $q_{t+1}$. This asset may be land, or security (Santos and Woodford , 1997), or stock (Kocherlakota , 1992)...

Table 1: Household i's balance sheet at date $t$

\begin{tabular}{ll|ll}
\hline \hline & Expenditures & Revenues & \\
\hline Consumption & $p_{t} c_{i, t}$ & $\theta^{i} \pi_{t}$ & share of profit \\
\hline Capital investment & $p_{t}\left(k_{i, t+1}-(1-\delta) k_{i, t}\right)$ & $r_{t} k_{i, t}$ & $\begin{array}{l}\text { capital return } \\
\text { from date } t-1\end{array}$ \\
\hline Financial asset & $q_{t} a_{i, t}$ & $\left(q_{t}+p_{t} \xi_{t}\right) a_{i, t-1}$ & $\begin{array}{l}\text { financial delivery } \\
\text { from date } t-1\end{array}$ \\
\hline \hline
\end{tabular}

Each household $i$ takes the sequence of prices $(p, q, r)=\left(p_{t}, q_{t}, r_{t}\right)_{t=0}^{\infty}$ as given and solves the following problem

$$
\begin{aligned}
\left(P_{i}(p, q, r)\right): & \max _{\left(c_{i, t}, k_{i, t+1}, a_{i, t}\right)_{t=0}^{+\infty}}\left[\sum_{t=0}^{+\infty} \beta_{i}^{t} u_{i}\left(c_{i, t}\right)\right] \\
\text { subject to : } & k_{i, t+1} \geq 0 \\
\text { budget constraint : } & p_{t}\left(c_{i, t}+k_{i, t+1}-(1-\delta) k_{i, t}\right)+q_{t} a_{i, t} \\
& \leq r_{t} k_{i, t}+\left(q_{t}+p_{t} \xi_{t}\right) a_{i, t-1}+\theta_{t}^{i} \pi_{t}
\end{aligned}
$$

borrowing constraint: $\quad\left(q_{t+1}+p_{t+1} \xi_{t+1}\right) a_{i, t} \geq-f^{i}\left[p_{t+1}(1-\delta)+r_{t+1}\right] k_{i, t+1},(4)$

where $f^{i} \in[0,1]$ is borrowing limit of agent $i . f^{i}$ is an exogenous parameter and set by law. This parameter can be viewed as an index of the financial development of the economy

In our setup, the borrowing constraint is endogenous. Agent $i$ can borrow an amount but the repayment of this amount does not exceed a fraction of the market value of his physical capital. This fraction, $f^{i}$, is less than 1 , i.e., the market value of collateral of each agent is greater than its debt. We can prove that borrowing constraint (4) is equivalent to $q_{t} a_{i, t} \geq-f^{i} p_{t} k_{i, t+1} \cdot{ }^{7}$

For each period, there is a representative firm which takes prices $\left(p_{t}, r_{t}\right)$ as given and maximizes its profit by choosing physical capital amount $K_{t}$.

$$
\left(P\left(p_{t}, r_{t}\right)\right): \quad \max _{K_{t} \geq 0}\left[p_{t} F_{t}\left(K_{t}\right)-r_{t} K_{t}\right]
$$

$\left(\theta_{t}^{i}\right)_{i=1}^{m}$ is the share of profit at date t. $\theta_{i}:=\left(\theta_{t}^{i}\right)_{t}$ is exogenous, $\theta_{t}^{i} \geq 0$ for all $i$ and $\sum_{i=1}^{m} \theta_{t}^{i}=1$.

\footnotetext{
${ }^{7}$ See Remark 4.1.
} 


\subsection{Equilibrium}

We define an infinite-horizon sequence of prices and quantities by

$$
\left(p, q, r,\left(c_{i}, k_{i}, a_{i}\right)_{i=1}^{m}, K, L\right)
$$

where, for each $i=1, \ldots, m$,

$$
\begin{aligned}
\left(c_{i}, k_{i}, a_{i}\right) & :=\left(\left(c_{i, t}\right)_{t=0}^{+\infty},\left(k_{i, t+1}\right)_{t=0}^{+\infty},\left(a_{i, t}\right)_{t=0}^{+\infty}\right) \in \mathbb{R}_{+}^{+\infty} \times \mathbb{R}^{+\infty} \times \mathbb{R}_{+}^{+\infty} \times \mathbb{R}^{+\infty} \\
(p, r, q) & :=\left(\left(p_{t}\right)_{t=0}^{+\infty},\left(r_{t}\right)_{t=0}^{+\infty},\left(q_{t}\right)_{t=0}^{+\infty}\right) \in \mathbb{R}^{+\infty} \times \mathbb{R}_{+}^{+\infty} \times \mathbb{R}^{+\infty} \\
(K) & :=\left(\left(K_{t}\right)_{t=0}^{+\infty}\right) \in \mathbb{R}_{+}^{+\infty}
\end{aligned}
$$

We also denote $z_{0}:=(p, q, r), z_{i}:=\left(c_{i}, k_{i}, a_{i}\right)$ for each $i=1, \ldots, m, z_{m+1}=(K)$ and $z=\left(z_{i}\right)_{i=0}^{m+1}$.

Denote $\mathcal{E}$ the economy which is characterized by a list

$$
\left(\left(u_{i}, \beta_{i}, k_{i, 0}, a_{i,-1}, f^{i}, \theta^{i}\right)_{i=1}^{m},\left(F_{t}, \xi_{t}\right)_{t=0}^{\infty}, \delta\right) .
$$

Definition 1. A sequence of prices and quantities $\left(\bar{p}_{t}, \bar{q}_{t}, \bar{r}_{t},\left(\bar{c}_{i, t}, \bar{k}_{i, t+1}, \bar{a}_{i, t}\right)_{i=1}^{m}, \bar{K}_{t}\right)_{t=0}^{+\infty}$ is an equilibrium of the economy $\mathcal{E}$ if the following conditions are satisfied:

(i) Price positivity: $\bar{p}_{t}, \bar{q}_{t}, \bar{r}_{t}>0$ for $t \geq 0$.

(ii) Market clearing: at each $t \geq 0$,

$$
\begin{aligned}
\text { good : } & \sum_{i=1}^{m}\left(\bar{c}_{i, t}+\bar{k}_{i, t+1}-(1-\delta) \bar{k}_{i, t}\right)=F_{t}\left(\bar{K}_{t}\right)+\xi_{t}, \\
\text { capital }: & \bar{K}_{t}=\sum_{i=1}^{m} \bar{k}_{i, t}, \\
\text { financial asset : } & \sum_{i=1}^{m} \bar{a}_{i, t}=1 .
\end{aligned}
$$

(iii) Optimal consumption plans: for each $i,\left(\bar{c}_{i, t}, \bar{k}_{i, t+1}, \bar{a}_{i, t}\right)_{t=0}^{\infty}$ is a solution of the problem $\left(P_{i}(\bar{p}, \bar{q}, \bar{r})\right)$.

(iv) Optimal production plan: for each $t \geq 0, \bar{K}_{t}$ is a solution of the problem $\left(P\left(\bar{p}_{t}, \bar{r}_{t}\right)\right)$.

The following result proves that aggregate capital and consumption supplies are bounded for the product topology.

Lemma 1. 1. Capital and consumption supplies are in a compact set for the product topology. 
2. Moreover, they are uniformly bounded if $\left(\xi_{t}\right)_{t}$ are uniformly bounded and there exists $t_{0}$ and an increasing, concave function $G$ such that the two following conditions are satisfied: (i) for every $t \geq t_{0}$ we have $F_{t}(K) \leq G(K)$ for every $K$, (ii) there exists $x>0$ such that $G(y)+(1-\delta) y+\sup _{t} \xi_{t} \leq y$ for every $y \geq x .^{8}$

Proof. Note that $\sum_{i=1}^{m} c_{i, t}+K_{t+1} \leq(1-\delta) K_{t}+F_{t}\left(K_{t}\right)$ for every $t \geq 0$

Denote

$$
\begin{aligned}
D_{0} & :=F_{0}\left(K_{0}\right)+(1-\delta) K_{0}+\xi_{0}, \\
D_{t} & :=F_{t}\left(D_{t-1}\right)+(1-\delta) D_{t-1}+\xi_{t} \quad \forall t \geq 0 .
\end{aligned}
$$

Then $\sum_{i=1}^{m} c_{i, t}+K_{t+1} \leq D_{t}$ for every $t \geq 0$. Since $D_{t}$ is exogenous, capital and consumption supplies are in a compact set for the product topology.

We now assume that time $t_{0}$ and the function $G$ (in the statement of Lemma 1) exist. Let denote $\xi:=\sup _{t} \xi_{t}$. We are going to prove that $0 \leq K_{t} \leq \max \left\{D_{t_{0}}, x\right\}=$ : $K$. Indeed, $K_{t} \leq K$ for every $t<t_{0}$. For $t \geq t_{0}$, we have

$$
K_{t+1}=\sum_{i=1}^{m} k_{i, t+1} \leq G\left(K_{t}\right)+(1-\delta) K_{t}+\xi .
$$

Then $K_{t_{0}} \leq G\left(K_{t_{0}-1}\right)+(1-\delta) K_{t_{0}-1}+\xi \leq G(K)+(1-\delta) K+\xi \leq K$. Iterating the argument, we find $K_{t} \leq K$ for each $t \geq 0$.

Consumptions are bounded because $\sum_{i=1}^{m} c_{i, t} \leq F_{t}\left(K_{t}\right)+(1-\delta) K_{t}+\xi$.

\section{The existence of equilibrium}

Standard assumptions are required.

Assumption (H1): $u_{i}$ is in $C^{1}, u_{i}(0)=0, u_{i}^{\prime}(0)=+\infty$, and $u_{i}$ is strictly increasing, concave, continuously differentiable.

Assumption (H2): $F_{t}(\cdot)$ is strictly increasing, concave, continuously differentiable, $F_{t}(0) \geq 0$.

Assumption (H3): For every $t \geq 0,0<\xi_{t}<\infty$.

Assumption (H4): At initial period $0, k_{i, 0}, a_{i,-1} \geq 0$, and $\left(k_{i, 0}, a_{i,-1}\right) \neq(0,0)$ for $i=1, \ldots, m$. Moreover, we assume that $\sum_{i=1}^{m} a_{i,-1}=1$ and $K_{0}:=\sum_{i=1}^{m} k_{i, 0}>0$.

\footnotetext{
${ }^{8}$ Condition (i) and (ii) are satisfied if $\sup _{t} \xi_{t}<\infty$ and the technology is stationary such that $F^{\prime}(\infty)<\delta$ (this condition is satisfied for Cobb Douglas production function). Indeed, $F^{\prime}(\infty)<\delta$ implies that $F^{\prime}(K)<\delta$ and then $F(K)-\delta K$ is decreasing for $K$ large enough. By combining with the fact that $\lim _{K \rightarrow \infty} \frac{F(K)}{K}=F^{\prime}(\infty)$, we obtain that $F(K)-\delta K<0$ for every $K$ large enough and $\lim _{K \rightarrow \infty}(F(K)-\delta K)=-\infty$.
} 
Remark 3.1. Here we differ from Becker, Bosi, Le Van, and Seegmuller (2014) by allowing non-stationary technology. We also accept the AK production technology.

First, we prove the existence of equilibrium for each $T$ - truncated economy $\mathcal{E}^{T}$. Second, we show that this sequence of equilibria converges for the product topology to an equilibrium of our economy $\mathcal{E}$. The value added in our proof is that we do not need that aggregate capital stocks are uniformly bounded, and we allow nonstationary technologies. Moreover, incorporating financial market with borrowing constraints also requires some new techniques in order to prove the existence of intertemporal equilibrium.

To prove the existence of equilibrium for $T$ - truncated economy $\mathcal{E}^{T}$, we prove the existence of the bounded economy $\mathcal{E}_{b}^{T}$ and then by using the concavity of the utility function, we will prove that such equilibrium is also an equilibrium of $\mathcal{E}^{T}$.

\subsection{The existence of equilibrium for $T$ - truncated economy $\mathcal{E}^{T}$}

We define $T$ - truncated economy $\mathcal{E}^{T}$ as $\mathcal{E}$ but there are no activities from period $T+1$ to the infinity, i.e., $c_{i, t}=a_{i, t-1}=k_{i, t}=K_{t}=0$ for every $i=1, \ldots, m, t \geq T+1$. Then we define the bounded economy $\mathcal{E}_{b}^{T}$ as $\mathcal{E}^{T}$ but all variables (consumption demand, capital supply, asset holding, capital demand) are in a compact set, say $\mathcal{S}_{b} .{ }^{9}$ See Appendix for details.

Lemma 2. Under Assumptions (H1)-(H4), there exists an equilibrium for $\mathcal{E}_{b}^{T}$.

Proof. See Appendix 8.1.

Let's consider $\left(p_{t}, q_{t}, r_{t},\left(c_{i, t}, k_{i, t+1}, a_{i, t}\right)_{i=1}^{m}, K_{t}\right)_{t=0}^{T}$ an equilibrium of the economy $\mathcal{E}_{b}^{T}$. Borrowing constraint (4) implies that

$$
\begin{aligned}
-a_{i, t} & \leq \frac{f^{i}\left[p_{t+1}(1-\delta)+r_{t+1}\right] k_{i, t+1}}{q_{t+1}+p_{t+1} \xi_{t+1}} \leq f^{i} \frac{k_{i, t+1}}{\xi_{t+1}}\left(1-\delta+\frac{r_{t+1}}{p_{t+1}}\right) \\
& \leq f^{i} \frac{(1-\delta) K_{t+1}+F_{t+1}\left(K_{t+1}\right)}{\xi_{t+1}} \leq \frac{D_{t+1}}{\xi_{t+1}}
\end{aligned}
$$

By combining with the fact that $\sum_{i=1}^{m} a_{i, t}=1$, we see that $\left(a_{i, t}\right)_{t=0}^{T}$ is in a compact set of $\mathbb{R}^{T+1}$. Therefore, we conclude that $\left(p_{t}, q_{t}, r_{t},\left(c_{i, t}, k_{i, t+1}, a_{i, t}\right)_{i=1}^{m}, K_{t}\right)_{t=0}^{T}$ is in a compact set, say $\mathcal{S}$ of $\mathbb{R}^{3 m+4}$. This compact set does not depend on the set $\mathcal{S}_{b}$. Hence, we can choose $\mathcal{S}_{b}$ big enough such that $\mathcal{S} \subset \mathcal{S}_{b}$. By this way, each equilibrium of $\mathcal{E}_{b}^{T}$ is also an equilibrium of $\mathcal{E}^{T}$.

Lemma 3. An equilibrium of $\mathcal{E}_{b}^{T}$ is an equilibrium for $\mathcal{E}^{T}$.

Proof. See Appendix 8.2.

\footnotetext{
${ }^{9}$ In order to use Kakutani's theorem, we need to introduce $\mathcal{E}_{b}^{T}$.
} 


\subsection{The existence of an equilibrium in $\mathcal{E}$}

To take the limit of sequence of equilibria, we need the following assumption.

Assumption (H5): For each agent $i$, her utility is finite

$$
\sum_{t=0}^{\infty} \beta_{i}^{t} u_{i}\left(D_{t}\left(F, \delta, K_{0}, \xi_{0}, \ldots, \xi_{t}\right)\right)<\infty .
$$

Remark 3.2. With stationary technology, condition 7 is satisfied if there exists $b<$ $\infty$ such that, for every $i \in\{1, \ldots, m\}$,

$$
\begin{aligned}
& \sum_{t=0}^{\infty} \beta_{i}^{t} \max _{s \leq t}\left\{\xi_{s}\right\}<\infty, \\
& \sum_{t=0}^{\infty} \beta_{i}^{t}\left(F^{\prime}(b)+1-\delta\right)^{t} \max _{s \leq t}\left\{\xi_{s}, 1\right\}<\infty .
\end{aligned}
$$

Proof. See Appendix 8.4.

Note that there exist some cases where although $F^{\prime}(\infty)>\delta$ and $\left(\xi_{t}\right)_{t}$ are not uniformly bounded, but conditions (8) and (9) still hold. For example, if there exist $b<\infty$ and $\alpha>1$ such that $\xi_{t} \leq \alpha^{t}$ and $\alpha \beta_{i}\left(F^{\prime}(b)+1-\delta\right)<1$, then conditions (8) and (9) hold.

Theorem 1. Under Assumptions (H1)-(H5), there exists an equilibrium in the infinite-horizon economy $\mathcal{E}$.

Proof. See Appendix 8.3. We consider the limit of sequences of equilibria in $\mathcal{E}^{T}$, when $T \rightarrow \infty$. We use convergence for the product topology.

\section{Financial market vs productive sector}

In this section, we will study the interaction between the financial market and the productive sector. For simplicity, we only consider stationary technology.

Let $\left(p_{t}, q_{t}, r_{t},\left(c_{i, t}, k_{i, t+1}, a_{i, t}\right)_{i=1}^{m}, K_{t}\right)_{t}$ be an equilibrium. Denote $\mu_{i, t}, \nu_{i, t+1}$ the multiplier associated with the budget constraint, the borrowing constraint, respectively, of the agent $i$ at date $t$. Denote $\lambda_{i, t+1}$ the multiplier associated with constraint $k_{i, t+1} \geq 0$. We have

$$
\begin{aligned}
\beta_{i}^{t} u_{i}^{\prime}\left(c_{i, t}\right) & =p_{t} \mu_{i, t} \\
p_{t} \mu_{i, t} & =\left(r_{t+1}+(1-\delta) p_{t+1}\right)\left(\mu_{i, t+1}+f^{i} \nu_{i, t+1}\right)+\lambda_{i, t+1} \\
q_{t} \mu_{i, t} & =\left(q_{t+1}+p_{t+1} \xi_{t+1}\right)\left(\mu_{i, t+1}+\nu_{i, t+1}\right) .
\end{aligned}
$$

Note that $k_{i, t+1} \lambda_{i, t+1}=0$ and

$$
\nu_{i, t+1}\left(\left(q_{t+1}+p_{t+1} \xi_{t+1}\right) a_{i, t}+f^{i}\left(p_{t+1}(1-\delta)+r_{t+1}\right) k_{i, t+1}\right)=0 .
$$


Lemma 4. We have, for each $t$,

$$
\frac{q_{t}}{q_{t+1}+p_{t+1} \xi_{t+1}}=\max _{i}\left\{\frac{\mu_{i, t+1}}{\mu_{i, t}}\right\} \leq \frac{p_{t}}{r_{t+1}+(1-\delta) p_{t+1}} .
$$

Moreover, the equality holds if there exists $i$ such that $k_{i, t+1}>0$.

Proof. Since $\sum_{i=1}^{m} a_{i, t}=1$, there exists $i$ such that $a_{i, t}>0$, and then $\nu_{i, t+1}=0$. As a consequence, we get

$$
\frac{q_{t}}{q_{t+1}+p_{t+1} \xi_{t+1}}=\max _{i}\left\{\frac{\mu_{i, t+1}}{\mu_{i, t}}\right\}
$$

It is easy to see that $\frac{p_{t}}{r_{t+1}+(1-\delta) p_{t+1}} \geq \max _{i}\left\{\frac{\mu_{i, t+1}}{\mu_{i, t}}\right\}$. Assume that $k_{i, t+1}>0$, we have $\lambda_{i, t+1}=0$, and then

$$
\frac{p_{t}}{r_{t+1}+(1-\delta) p_{t+1}}=\frac{\mu_{i, t+1}+f^{i} \nu_{i, t+1}}{\mu_{i, t}} \leq \frac{\mu_{i, t+1}+\nu_{i, t+1}}{\mu_{i, t}}=\frac{q_{t}}{q_{t+1}+p_{t+1} \xi_{t+1}}
$$

Therefore, we have $\frac{p_{t}}{r_{t+1}+(1-\delta) p_{t+1}}=\max _{i}\left\{\frac{\mu_{i, t+1}}{\mu_{i, t}}\right\}$.

Remark 4.1. According to Lemma 4, we have that

$$
f^{i}\left(p_{t+1}(1-\delta)+r_{t+1}\right) k_{i, t+1}=f^{i} \frac{p_{t}\left(q_{t+1}+\xi_{t+1} p_{t+1}\right)}{q_{t}} k_{i, t+1} .
$$

As a consequence, borrowing constraint (4) is equivalent to $q_{t} a_{i, t} \geq-f^{i} p_{t} k_{i, t+1}$.

In our framework, consumers have two possibilities to invest: in financial asset and/or in physical capital. We would like to know when consumers invest in physical capital and/or in financial asset. Note that the real return of the physical capital is $\frac{r_{t+1}}{p_{t+1}}+1-\delta$, and the physical capita's maximum real return is $F^{\prime}(0)+1-\delta$. The real return of the financial asset is $\frac{\frac{q_{t+1}}{p_{t+1}+\xi_{t+1}}}{\frac{q_{t}}{p_{t}}}$.

The following results show the respective roles of the productivity and the financial dividends.

Lemma 5. If $\frac{\frac{q_{t+1}}{p_{t+1}+\xi_{t+1}}}{\frac{q_{t}}{p_{t}}} \geq\left(F^{\prime}(0)+1-\delta\right)$ then consumers do not invest in physical capital, i.e., $K_{t+1} \stackrel{p_{t}}{=} 0$.

Proof. Suppose that $\frac{\frac{q_{t+1}}{p_{t+1}+\xi_{t+1}}}{\frac{q_{t}}{p_{t}}} \geq\left(F^{\prime}(0)+1-\delta\right)$. If $K_{t+1}>0$, there exists $i \in$ $\{1, \cdots, m\}$ such that $k_{i, t+1}>0$. According to Lemma 4 , we have

$$
\max _{i}\left\{\frac{\beta_{i} u_{i}^{\prime}\left(c_{i, t+1}\right)}{u_{i}^{\prime}\left(c_{i, t}\right)}\right\}=\frac{1}{\frac{r_{t+1}}{p_{t+1}}+1-\delta} .
$$


FOC of $K_{t+1}$ implies that $\frac{r_{t+1}}{p_{t+1}}=F^{\prime}\left(K_{t+1}\right)<F^{\prime}(0)$, hence $\max _{i}\left\{\frac{\beta_{i} u_{i}^{\prime}\left(c_{i, t+1}\right)}{u_{i}^{\prime}\left(c_{i, t}\right)}\right\}>$ 1 $\overline{F^{\prime}(0)+1-\delta}$.

We also have $\max _{i}\left\{\frac{\beta_{i} u_{i}^{\prime}\left(c_{i, t+1}\right)}{u_{i}^{\prime}\left(c_{i, t}\right)}\right\}=\frac{\frac{q_{t}}{p_{t}}}{\frac{q_{t+1}}{p_{t+1}}+\xi_{t+1}}$. This implies that

$$
\frac{\frac{q_{t}}{p_{t}}}{\frac{q_{t+1}}{p_{t+1}}+\xi_{t+1}}>\frac{1}{F^{\prime}(0)+1-\delta},
$$

contradiction!

Lemma 5 says that if the maximum real return of the physical capital is less than the financial asset's return, households do not invest in the physical capital.

Economic recession: We say that there is an economic recession at date $t$ if no one invests in this sector, i.e., the aggregate capital equals zero, $K_{t}=0$. The following result points out the importance of the competitiveness of the productive sector.

Proposition 1. Assume that there exists $\xi>0$ such that $\xi_{t} \geq \xi$ for every $t \geq 0$ and $F^{\prime}(0) \leq \delta$. Then there is an infinite sequence $\left(t_{n}\right)_{n=0}^{\infty}$ such that $K_{t_{n}}=0$ for every $n \geq 0$.

Proof. We claim that there exists an infinite increasing sequence $\left(t_{n}\right)_{n=0}^{\infty}$ such that $\frac{q_{t_{n}}}{p_{t_{n}}}+\xi_{t_{n}}>\frac{q_{t_{n}-1}}{p_{t_{n}-1}}$ for every $n \geq 0$.

Indeed, if not, there exists $t_{0}$ such that $\frac{q_{t+1}}{p_{t+1}}+\xi_{t+1} \leq \frac{q_{t}}{p_{t}}$ for every $t \geq t_{0}$. Combining with $\xi_{t} \geq \xi$ for every $t \geq 0$ and by using induction argument, we can easily prove that

$$
\frac{q_{t_{0}}}{p_{t_{0}}} \geq \frac{q_{t+t_{0}}}{p_{t+t_{0}}}+t \xi
$$

for every $t \geq 0$. Let $t \rightarrow \infty$, we have $\frac{q_{t_{0}}}{p_{t_{0}}}=\infty$, contradiction! ${ }^{10}$

Therefore, there exists a sequence $\left(t_{n}\right)$ such that for every $n \geq 0, \frac{q_{t_{n}}}{p_{t_{n}}}+\xi_{t_{n}}>$ $\frac{q_{t_{n}-1}}{p_{t_{n}-1}}>1 \geq F^{\prime}(0)+1-\delta$. Lemma 5 implies that $K_{t_{n}}=0$ for every $n \geq 0$.

Proposition 1 shows that if the productivity is low, i.e. $F^{\prime}(0)<\delta$, recession will appear at infinitely many dates. Since the bound $\xi$ does not depend on the technology, we see that economic recession is not from the financial market, but from the fact that the productive sector is not competitive. This result suggests that we should invest in technology to improve the competitiveness of productive sectors in order to avoid recession.

We illustrate Proposition 1 by the following example.

\footnotetext{
${ }^{10}$ Our result in Proposition 1 is still valid if the condition " $\xi_{t} \geq \xi>0$ for every $t \geq 0$ " is replaced by " $\sum_{t=0}^{\infty} \xi_{t}=\infty "$.
} 
Example 1. ( $K_{t}=0$ for every $\left.t \geq 1\right)$

Consider an economy with two agents $i$ and $j$ such that

$$
\begin{aligned}
& \beta_{i}=\beta_{i}=\beta \in(0,1), \quad u_{i}(x)=u_{j}(x)=\frac{x^{1-\sigma}}{1-\sigma}, \\
& K_{0}>0, \quad \beta\left(F^{\prime}(0)+1-\delta\right) \leq 1, \\
& a_{i,-1}=\theta^{i}=\frac{k_{i, 0}}{K_{0}}=a \in(0,1), \\
& \xi_{0} ; \quad \xi_{t}=\xi \quad \forall t \geq 1, f^{i}=f^{j}=0,
\end{aligned}
$$

where $q_{0}, \xi_{0}, \xi, K_{0}$ are such that

$$
\begin{aligned}
& 1 \geq \beta\left(F^{\prime}(0)+1-\delta\right)\left(\frac{F\left(K_{0}\right)+(1-\delta) K_{0}+\xi_{0}}{\xi}\right)^{\sigma}, \\
& \left(\frac{F\left(K_{0}\right)+(1-\delta) K_{0}+\xi_{0}}{\xi}\right)^{\sigma}=\frac{q_{0}}{\xi} \frac{1-\beta}{\beta} .
\end{aligned}
$$

An equilibrium is given by the following

Allocations:

$$
\begin{aligned}
& a_{i, t}=a, \quad a_{j, t}=1-a \quad \forall t \geq 1, \\
& k_{i, t}=k_{j, t}=0 \quad \forall t \geq 1, \\
& c_{i, 0}=a\left(F\left(K_{0}\right)+(1-\delta) K_{0}+\xi_{0}\right), \quad c_{i, t}=a \xi, \quad \forall t \geq 1, \\
& c_{j, 0}=(1-a)\left(F\left(K_{0}\right)+(1-\delta) K_{0}+\xi_{0}\right), \quad c_{j, t}=(1-a) \xi, \quad \forall t \geq 1,
\end{aligned}
$$

Prices: $\quad p_{t}=1 \quad \forall t ; r_{0}=F^{\prime}\left(K_{0}\right), \quad r_{t}=F^{\prime}(0) \quad \forall t \geq 1$,

$$
q_{0}, \quad q_{t}=\xi \frac{\beta}{1-\beta} \quad \forall t \geq 1
$$

Proof. See Appendix 8.4.

We say that the productive sector is competitive if $\min _{i} \beta_{i}\left(F^{\prime}(0)+1-\delta\right)>1$. It is extremely competitive if $F^{\prime}(0)=+\infty$. Note that $\left(F^{\prime}(0)+1-\delta\right) \min _{i} \beta_{i}>$ 1 is equivalent to $F^{\prime}(0)>\frac{1}{\min _{i} \beta_{i}}-1+\delta$, where $\frac{1}{\min _{i} \beta_{i}}-1+\delta$ is the highest investment cost if we use some interest rates to define the discount factors $\beta_{i}$. In Proposition 2 and its two corollaries, we consider the case where the productive sector is competitive.

Proposition 2. Assume that there exist $t \geq 0, T \geq 1$ such that $\xi_{t} \geq \xi_{t+T}$. If $\left(F^{\prime}(0)+1-\delta\right) \min _{i} \beta_{i}>1$, there exists $1 \leq s \leq T$ such that $K_{t+s}>0$.

Proof. See Appendix 8.4.

Corollary 1. Assume that there exists an infinite decreasing sequence $\left(\xi_{t_{n}}\right)_{n=0}^{\infty}$, i.e., $\xi_{t_{n}} \geq \xi_{t_{n+1}}$ for every $n \geq 0$. If $\left(F^{\prime}(0)+1-\delta\right) \min _{i} \beta_{i}>1$, there exists an infinite sequence $\left(\tau_{n}\right)_{n \geq 0}$ such that $K_{\tau_{n}}>0$ for every $n \geq 0$ at any equilibrium.

Corollary 2. Assume that $\xi_{t}=\xi>0$ for every $t \geq 0$. If $\left(F^{\prime}(0)+1-\delta\right) \min _{i} \beta_{i}>1$, we have $K_{t}>0$ for every $t \geq 1$ at any equilibrium. 
We continue our exposition by the following result:

Proposition 3. If $\beta_{i}\left(F^{\prime}(0)+1-\delta\right) u_{i}^{\prime}\left(\xi_{t+1}\right)>u_{i}^{\prime}\left(\frac{F\left(K_{t}\right)+(1-\delta) K_{t}+\xi_{t}}{m}\right)$ for every $i=1, \ldots, m$, we have $K_{t+1}>0$.

Proof. See Appendix 8.4.

On the one hand, Proposition 3 proves that if the productivity $F^{\prime}(0)=\infty$ then $K_{t+1}>0$ at equilibrium. On the other hand, Proposition 3 also shows that the financial market plays an important role in the productive sector. Indeed, consider an equilibrium where $K_{t}=0$. Assume also that $\xi_{t}$ is high enough such that, for every $i$,

$$
\beta_{i}(1-\delta) u_{i}^{\prime}\left(\xi_{t+1}\right)>u_{i}^{\prime}\left(\frac{\xi_{t}}{m}\right)
$$

According to Proposition 3, we get that $K_{t+1}>0$. This is due to the fact that part of the financial dividend is used to buy physical capital.

Economic collapse: We say that the economy falls in collapse if $\liminf _{t \rightarrow \infty} K_{t}=0$. In what follows, we will find out factors which help us to avoid economic collapse.

A natural question is whether the aggregate capital stock $K_{t}$ is bounded from below. To answer this question, the following result is useful:

Proposition 4. Given $K \geq 0, \xi>0$, let $G_{i}(K, \xi)$ be defined by

$$
u_{i}^{\prime}\left(G_{i}(K, \xi)\right)=\left(F^{\prime}(K)+1-\delta\right) \beta_{i} u_{i}^{\prime}(F(K)+(1-\delta) K+\xi) .
$$

At equilibrium, there exists $i$ such that

$$
\xi_{t} \leq K_{t+1}+m G_{i}\left(K_{t+1}, \xi_{t+1}\right)
$$

Proof. See Appendix 8.4.

Interpretation: by definition, the quantity $G_{i}\left(K_{t+1}, \xi_{t+1}\right)$ is an upper bound of the consumption good of the agent $i$ at date $t$ when this agent expects that the aggregate capital at date $t+1$ is $K_{t+1}$. If we choose $i$ such that $G_{i}\left(K_{t+1}, \xi_{t+1}\right)=$ $\max _{j} G_{j \in\{1, \cdots, m\}}\left(K_{t+1}, \xi_{t+1}\right)$ then $m G_{i}\left(K_{t+1}, \xi_{t+1}\right)$ is an upper bound of the aggregate consumption at date $t$. As a consequence, we see that

$$
m G_{i}\left(K_{t+1}, \xi_{t+1}\right)+K_{t+1} \geq \sum_{i=1}^{m} c_{i, t}+K_{i, t+1} \geq \xi_{t} .
$$

Since $u^{\prime}, F^{\prime}$ are decreasing and $F$ is increasing, we can see that $G_{i}\left(K_{t+1}, \xi_{t+1}\right)$ is increasing in $K_{t+1}$ and $\xi_{t+1}$. Moreover, we have $G_{i}\left(0, \xi_{t+1}\right)=0$ if $F^{\prime}(0)=\infty$.

In the following result, by using (16) and the properties of the function $G_{i}$, we can give a lower bound of $K_{t+1}$. 
Corollary 3. 1. Assume that $\xi_{t}>m G_{i}\left(0, \xi_{t+1}\right)$ for every $i$. At equilibrium, we have

$$
K_{t+1} \geq \min _{i}\left\{B_{i}\left(\xi_{t}, \xi_{t+1}\right)\right\}>0
$$

where $B_{i}\left(\xi_{t}, \xi_{t+1}\right)$ is defined $d^{11}$ by

$$
\xi_{t}=B_{i}\left(\xi_{t}, \xi_{t+1}\right)+m G_{i}\left(B_{i}\left(\xi_{t}, \xi_{t+1}\right), \xi_{t+1}\right) .
$$

2. Assume that $\xi_{t}=\xi>0$ for any $t$. We also assume that $\xi>m G_{i}(0, \xi)$ for every $i$. Then

$$
K_{t+1} \geq \min _{i}\left\{B_{i}(\xi, \xi)\right\}>0
$$

which means that $\left(K_{t}\right)$ is uniformly bounded away from zero.

Note that if $G_{i}\left(K_{t+1}, \xi_{t+1}\right) \leq \xi_{t}$ then the inequality (16) does not make sense. That's why we need the condition $\xi_{t}>m G_{i}\left(0, \xi_{t+1}\right) .{ }^{12}$ Under this condition, $K_{t+1}$ is bounded from below by $\min _{i}\left\{B_{i}\left(\xi_{t}, \xi_{t+1}\right)\right\}$ which is a strictly positive exogenous quantity. This quantity may be not uniformly bounded away from zero.

In the second part of Corollary 3 we give simple conditions under which there is no economic collapse.The economic intuition for this fact is the following: Condition $\xi>m G_{i}(0, \xi)$ is satisfied if and only if $F^{\prime}(0)$ is high, i.e., the productivity is high. When the productivity is high, ${ }^{13}$ agents invest in the productive sector, and therefore economic collapse will be avoided.

We end this section by the following result showing that a fluctuation of $\left(\xi_{t}\right)$ may create a fluctuation of $\left(K_{t}\right)$.

\section{Corollary 4. (Fluctuation of the capital stocks)}

Assume that

(i) $\beta_{i}=\beta, u_{i}(c)=\frac{c^{1-\sigma}}{1-\sigma}$, and $F^{\prime}(0) \leq \delta$.

(ii) $\xi_{2 t} \rightarrow \xi^{e}, \xi_{2 t+1} \rightarrow \xi^{o}$ when $t \rightarrow \infty$.

(iii) $\xi^{e}>\frac{m \xi^{o}}{\left(\beta\left(F^{\prime}(0)+1-\delta\right)\right)^{\frac{1}{\sigma}}}$.

We have

(i) There is an infinite sequence $\left(t_{n}\right)_{n=0}^{\infty}$ s.t. $K_{t_{n}}=0$ for every $n \geq 0$.

(ii) $\limsup K_{t}>0$.

\footnotetext{
${ }^{11}$ Note that $B_{i}\left(\xi_{t}, \xi_{t+1}\right)$ is increasing in $\xi_{t}$ and decreasing in $\xi_{t+1}$.

${ }^{12}$ This condition is satisfied if $\xi_{t}$ is high or/and $F^{\prime}(0)$ is high.

${ }^{13} F^{\prime}(0)$ may be finite.
} 
Proof. The first point is a direct consequence of Proposition 1. Let us prove the second point. Assume that $\lim \sup K_{t}=0$. According to (16), we have, for each $t$,

$$
\xi_{2 t} \leq K_{2 t+1}+m G_{i}\left(K_{2 t+1}, \xi_{2 t+1}\right)
$$

Let $t$ tend to infinity, we get $\xi^{e} \leq m G_{i}\left(0, \xi^{o}\right)$. Under Assumptions of Corollary 4, it can be computed that

$$
G_{i}\left(0, \xi^{o}\right)=\frac{\xi^{o}}{\left(\beta\left(F^{\prime}(0)+1-\delta\right)\right)^{\frac{1}{\sigma}}} .
$$

As a result, we obtain

$$
\xi^{e} \leq \frac{m \xi^{o}}{\left(\beta\left(F^{\prime}(0)+1-\delta\right)\right)^{\frac{1}{\sigma}}},
$$

which is an contradiction.

\section{On the efficiency of equilibria}

In this section, we study the efficiency of intertemporal equilibrium. First, following Malinvaud (1953), we define the efficiency of a capital path as follows.

Definition 2. Let $F_{t}$ be a production function, $\delta$ be the capital depreciation rate, $\left(\xi_{t}\right)_{t=0}^{\infty}$ is an exogenous positive sequence. A feasible path of capital is a positive sequence $\left(K_{t}\right)_{t=0}^{\infty}$ such that $0 \leq K_{t+1} \leq F_{t}\left(K_{t}\right)+(1-\delta) K_{t}+\xi_{t}$ for every $t \geq 0$ and $K_{0}$ is given. The aggregate feasible consumption at date $t$ is defined by

$$
C_{t}:=F_{t}\left(K_{t}\right)+(1-\delta) K_{t}+\xi_{t}-K_{t+1} .
$$

A feasible path is efficient if there is no other feasible path $\left(K_{t}^{\prime}\right)$ such that $C_{t}^{\prime} \geq C_{t}$ for every $t$ with strict inequality for some $t$.

Definition 3. We say that an intertemporal equilibrium is efficient if its aggregate feasible capital path $\left(K_{t}\right)$ is efficient.

Definition 4. We define the discount factor of the economy from initial date to date $t$ as follows

$$
Q_{0}:=1, \quad Q_{t}:=\prod_{s=1}^{t} \gamma_{s}, \quad t \geq 1
$$

where $\gamma_{t+1}:=\max _{i \in\{1, \ldots, m\}} \frac{\beta_{i} u_{i}^{\prime}\left(c_{i, t+1}\right)}{u_{i}^{\prime}\left(c_{i, t}\right)}$.

Lemma 6. An equilibrium is efficient if $\liminf _{t \rightarrow \infty} Q_{t} K_{t+1}=0$.

Proof. See Malinvaud (1953) and Bosi, Le Van, and Pham (2014). 
According to Lemma 4 we have at equilibrium

$$
\left(Q_{t+1}\left(1-\delta+\frac{r_{t+1}}{p_{t+1}}\right)-Q_{t}\right) K_{t+1}=0
$$

By using this relation and the same argument in Bosi, Le Van, and Pham (2014), we obtain that, for any feasible path $\left(K_{t}^{\prime}\right)$,

$$
\sum_{t=0}^{T} Q_{t} C_{t}+Q_{T} K_{T+1} \geq \sum_{t=0}^{T} Q_{t} C_{t}^{\prime}
$$

The condition $\liminf _{t \rightarrow \infty} Q_{t} K_{t+1}=0$ is a kind of transversality condition which allows us to obtain that

$$
\liminf _{T \rightarrow+\infty} \sum_{t=0}^{T} Q_{t}\left(C_{t}-C_{t}^{\prime}\right) \geq 0 .
$$

As a result, the path $\left(K_{t}, C_{t}\right)$ is efficient.

Becker, Dubey, and Mitra (2014) give an example of inefficient Ramsey equilibrium in a model with only physical capital. The production function in their model satisfies $F^{\prime}(\infty)=0$ and they consider full depreciation of the capital. The following result shows that financial dividends, for such models, may make production paths efficient. Actually, the result is more general.

Proposition 5. We assume that the production functions are stationary and concave, $F^{\prime}(\infty)<\delta$, and $\limsup _{t \rightarrow \infty} \xi_{t}<\infty$. If $\limsup _{t \rightarrow \infty} \xi_{t}>0$, every equilibrium is efficient.

Proof. Since technologies are stationary and $\limsup _{t \rightarrow \infty} \xi_{t}<\infty$, we easily see that $\left(K_{t}\right)$ is uniformly bounded (using Lemma 1).

Since $\lim \sup \xi_{t}>0$, there exists a constant $\Lambda$ and a sequence $\left(t_{n}\right)$ such that $K_{t_{n+1}} \leq \Lambda \xi_{t_{n}}^{t \rightarrow \infty}$ for every $n$ large enough.

According to Lemma 4, we have $\frac{q_{t}}{p_{t}} Q_{t}=\left(\frac{q_{t+1}}{p_{t+1}}+\xi_{t+1}\right) Q_{t+1}$. As a consequence, we obtain

$$
\frac{q_{0}}{p_{0}}=\sum_{t=1}^{\infty} Q_{t} \xi_{t}+\lim _{t \rightarrow \infty} \frac{q_{t}}{p_{t}} Q_{t} .
$$

Recall that $p_{0}, q_{0}>0$, hence $\sum_{t=1}^{\infty} Q_{t} \xi_{t}<\infty$. Therefore, we have $\lim _{t \rightarrow \infty} Q_{t} \xi_{t}=0$ which implies that $\lim _{n \rightarrow \infty} Q_{t_{n}} K_{t_{n}+1}=0$. According to Lemma 6 , the capital path is efficient.

\section{Bubbles}

We will first consider the productive sector and define physical asset bubble. Let $\left(p_{t}, q_{t}, r_{t},\left(c_{i, t}, k_{i, t+1}, a_{i, t}\right)_{i=1}^{m}, K_{t}\right)_{t}$ be an equilibrium. According to Lemma 4 , we have: 
Lemma 7. For each $t$, we have

$$
1 \geq\left(1-\delta+\frac{r_{t+1}}{p_{t+1}}\right) \gamma_{t+1}
$$

where $\gamma_{t+1}:=\max _{i \in\{1, \ldots, m\}} \frac{\beta_{i} u_{i}^{\prime}\left(c_{i, t+1}\right)}{u_{i}^{\prime}\left(c_{i, t}\right)}$. We have equality if $K_{t+1}>0$.

Definition 5. The expected return $\rho_{t+1}$ is defined by

$$
\max _{i \in\{1, \ldots, m\}} \frac{\beta_{i} u_{i}^{\prime}\left(c_{i, t+1}\right)}{u_{i}^{\prime}\left(c_{i, t}\right)}=\frac{1}{1-\delta+\rho_{t+1}}
$$

Note that we always have the following no-arbitrage condition

$$
\frac{1}{1-\delta+\rho_{t+1}}=\frac{\frac{q_{t}}{p_{t}}}{\frac{q_{t+1}}{p_{t+1}}+\xi_{t+1}} .
$$

Moreover, according to Lemma 7, we have $\rho_{t+1}=\frac{r_{t+1}}{p_{t+1}}=F_{t+1}^{\prime}\left(K_{t+1}\right)$ if $K_{t+1}>0$.

We now have $1=\left(1-\delta+\rho_{t}\right) \gamma_{t}$ and so $Q_{t}=\left(1-\delta+\rho_{t+1}\right) Q_{t+1}$ for each $t \geq 0$. By interating, we get

$$
\begin{aligned}
1 & =\left(1-\delta+\rho_{1}\right) Q_{1}=(1-\delta) Q_{1}+\rho_{1} Q_{1} \\
& =(1-\delta)\left(1-\delta+\rho_{2}\right) Q_{2}+\rho_{1} Q_{1}=(1-\delta)^{2} Q_{2}+(1-\delta) \rho_{2} Q_{2}+\rho_{1} Q_{1} \\
& =\cdots \\
& =(1-\delta)^{t} Q_{t}+\sum_{s=1}^{t}(1-\delta)^{t-1} \rho_{t} Q_{t} .
\end{aligned}
$$

Interpretation: In this framework, the physical capital can be viewed as a longlived asset whose price (in term of consumption good) at initial date equals 1 . If one buys one unit of the physical capital at date 0 , he or she will anticipate as follows:

1. At date 1 , one unit (from date 0 ) of this asset will give $(1-\delta)$ units of the physical capital and $\rho_{t}$ units of consumption good as its dividend. This argument is formalized by $1=(1-\delta) Q_{1}+\rho_{1} Q_{1}$.

2. At date $2,(1-\delta)$ units of the physical capital will give $(1-\delta)^{2}$ units of the physical capital and $(1-\delta) \rho_{2}$ units of consumption good. This argument is formalized by $(1-\delta) Q_{1}=(1-\delta)^{2} Q_{2}+(1-\delta) \rho_{2} Q_{2}$.

The fundamental value of the physical capital at date 0 can be defined by

$$
\sum_{t=1}^{\infty}(1-\delta)^{t-1} \rho_{t} Q_{t} .
$$

Definition 6. We say that there is a physical capital bubble if $1>\sum_{s=1}^{\infty}(1-\delta)^{t-1} \rho_{t} Q_{t}$. 
We state the necessary and sufficient conditions to have bubbles on the physical asset market.

Proposition 6. The three following statement are equivalent

(i) There is a physical capital bubble.

(ii) $\lim _{t \rightarrow \infty}(1-\delta)^{t} Q_{t}>0$.

(iii) $\sum_{t=1}^{\infty} \rho_{t}<+\infty$.

Proof. The proof is similar to the one in Bosi, Le Van, and Pham (2014).

Let us now move to the financial asset market. It is easy to obtain the following relation

$$
\begin{aligned}
\frac{q_{t}}{p_{t}} & =\gamma_{t+1}\left(\frac{q_{t+1}}{p_{t+1}}+\xi_{t+1}\right) \\
Q_{t} \frac{q_{t}}{p_{t}} & =Q_{t+1}\left(\frac{q_{t+1}}{p_{t+1}}+\xi_{t+1}\right) .
\end{aligned}
$$

Therefore, for each $t \geq 1$, we have

$$
\begin{aligned}
\frac{q_{0}}{p_{0}} & =\gamma_{1}\left(\frac{q_{1}}{p_{1}}+\xi_{1}\right)=Q_{1} \xi_{1}+\gamma_{1} \frac{q_{1}}{p_{1}}=Q_{1} \xi_{1}+\gamma_{1} \gamma_{2}\left(\frac{q_{2}}{p_{2}}+\xi_{2}\right) \\
& =Q_{1} \xi_{1}+Q_{2} \xi_{2}+Q_{2} \frac{q_{2}}{p_{2}} \\
& =\ldots=\sum_{s=1}^{t} Q_{s} \xi_{s}+Q_{t} \frac{q_{t}}{p_{t}}
\end{aligned}
$$

In our framework, the financial asset is a long-lived asset which gives dividends at each date.

1. At date 1 , one unit (from date 0 ) of this asset will give back 1 unit of the same asset and $\xi_{1}$ units of consumption good as its dividend. This is represented by $\frac{q_{0}}{p_{0}}=Q_{1} \xi_{1}+Q_{1} \frac{q_{1}}{p_{1}}$

2. At date 2, one unit of long lived asset will give one unit of the same asset and $\xi_{2}$ units of consumption good. This is represented by $Q_{1} \frac{q_{1}}{p_{1}}=Q_{2} \xi_{2}+Q_{2} \frac{q_{2}}{p_{2}}$, and so on.

This leads us to have the following concept:

Definition 7. The fundamental value of the financial asset is

$$
F V_{0}:=\sum_{t=1}^{+\infty} Q_{t} \xi_{t}
$$


The sequence $\left(Q_{t}\right)$ may not be in $l^{1}$, see Section 6.2.

Denote $b_{0}:=\lim _{t \rightarrow+\infty} Q_{t} \frac{q_{t}}{p_{t}}, b_{0}$ is called financial asset bubble. We have

$$
\frac{q_{0}}{p_{0}}=b_{0}+F V_{0}
$$

It means that the market price of the financial asset equals its fundamental value plus its bubble.

Definition 8. We say there is a bubble on financial asset if the price of financial asset is greater than its fundamental value: $\frac{q_{0}}{p_{0}}>F V_{0}$.

Remark 6.1. Our definitions of physical and financial bubbles still holds for nonstationary technologies.

We give another definition of low interest rates for the financial asset market. We recall budget constraints of agent $i$ at date $t-1$ and $t$.

$$
\begin{aligned}
p_{t-1}\left(c_{i, t-1}+k_{i, t}-(1-\delta) k_{i, t-1}\right)+q_{t-1} a_{i, t-1} & \leq r_{t-1} k_{i, t-1}+\left(q_{t-1}+p_{t-1} \xi_{t-1}\right) a_{i, t-1}+\theta^{i} \pi_{t-1} \\
p_{t}\left(c_{i, t}+k_{i, t+1}-(1-\delta) k_{i, t}\right)+q_{t} a_{i, t} & \leq r_{t} k_{i, t}+q_{t}\left(1+\frac{p_{t} \xi_{t}}{q_{t}}\right) a_{i, t-1}+\theta^{i} \pi_{t}
\end{aligned}
$$

One can interpret that if agent $i$ buys $a_{i, t-1}$ units of financial asset at date $t-1$ with price $q_{t-1}$, she will receive $\left(1+\frac{p_{t} \xi_{t}}{q_{t}}\right) a_{i, t-1}$ units of financial asset with price $q_{t}$ at date $t$. Therefore, $\frac{p_{t} \xi_{t}}{q_{t}}$ can be viewed as the real interest rate of the financial asset at date $t$.

Definition 9. We say that interest rates are low at equilibrium if

$$
\sum_{t=1}^{\infty} \frac{p_{t} \xi_{t}}{q_{t}}<\infty .
$$

Otherwise, we say that interest rates are high.

We now give a relationship between financial bubble and low interest rates of the financial asset market.

Proposition 7. There is a financial asset bubble if and only if interest rates are low.

Proof. See Le Van, Pham, and Vailakis (2014).

We now present our result on bubbles.

Proposition 8. (1) Assume that the production functions are stationary. Then at equilibrium there exists no bubble on the physical asset market.

(2) We assume that the production functions are stationary, $F^{\prime}(\infty)<\delta$ and $0<$ $\liminf _{t \rightarrow \infty} \xi_{t} \leq \limsup _{t \rightarrow \infty} \xi_{t}<\infty$. Then there is no bubble on the financial asset market. 
Proof. See Appendix 8.4.

The structure of physical capital is characterized by a list $\left(K_{0}, \delta,\left(F_{t}\right)_{t}\right)$ of the initial physical capital, the rate of depreciation, and production functions. The structure of financial asset is characterized by its dividends $\left(\xi_{t}\right)$. Our definition of bubbles is based on discount factors that are endogenously determined and depend on the structure of both physical capital and financial asset. As a consequence, the existence of physical (resp., financial) bubbles depends not only on the structure of this asset but also on the structure of financial asset (resp., physical capital.)

The first statement of Proposition 8 claims that with stationary technology and without any condition on $\left(\xi_{t}\right)$, physical bubble is ruled out.

In Becker, Bosi, Le Van, and Seegmuller (2014), they worked with an endogenous labor supply model and needed some specific conditions of the production function to ensure that the capital stocks are uniformly bounded; by using the boundedness of capital stocks, they proved that physical bubble is ruled out. However, we do not require any specific condition of the production function, and we also allow for AK technology. By the way, their result can be viewed as a particular case of our result.

In Bosi, Le Van, and Pham (2014) they considered a model with only physical capital and show that physical bubble exists if the technologies are given by $F_{t}(K)=$ $A_{t} K$ with $\sum_{t=1}^{\infty} A_{t}<\infty$. In our framework (with both physical capital and financial asset), however, this is not sufficient to have physical bubble because the following condition must be satisfied: ${ }^{14}$

$$
\sum_{t=1}^{+\infty} \frac{\xi_{t}}{(1-\delta)^{t}}<\infty
$$

As discussed above, the reason is that the structure of financial asset $\left(\xi_{t}\right)$ affects the discount factors $\left(Q_{t}\right)$ and the expected returns $\left(\rho_{t}\right)$, and therefore the existence of physical bubbles. According to condition (30), there is no physical bubble if dividends of financial asset are not too low in the sense that $\limsup _{t \rightarrow \infty} \xi_{t}>0$ whatever the form of technologies. In the following example we point out that there may be a physical bubble when the technology is not stationary and $\xi_{t}$ tends to zero.

Example 2. Assume that (15) is satisfied and Assume that $\beta_{i}=\beta, u_{i}(c)=\frac{c^{1-\sigma}}{1-\sigma}, \sigma \in$ $(0,1) ; F_{t}(K)=A_{t} K$ or $F_{t}(K)=A_{n} \ln (1+K)$ for any $t ; \sum_{t=1}^{\infty} A_{t}<\infty$. Assume that $\xi_{t+1}<\frac{(\beta(1-\delta))^{\frac{1}{\sigma}}}{m} \xi_{t}$ for any $t$.

Then there exists physical bubble. Indeed, condition (15) is satisfied since we have $\xi_{t+1}<\frac{(\beta(1-\delta))^{\frac{1}{\sigma}}}{m} \xi_{t}$. As a consequence, $K_{t}>0$ for any $t$, which implies that $\rho_{t}=F_{t}^{\prime}\left(K_{t}\right) \leq A_{t}$. According to Proposition 6, physical bubble exists. Observe also that Condition (30) is satisfied.

\footnotetext{
${ }^{14}$ This condition is followed by the proof of the first statement of Proposition 8 .
} 
We now discuss about the second statement of Proposition 8. With stationary technolgy, we need some additional conditions to eliminate financial bubbles. Conditions $F^{\prime}(\infty)<\delta$ and $\lim \sup \xi_{t}<\infty$ are natural and to ensure that the aggregate capital stocks are uniformly bounded from above. We also require $\liminf _{t \rightarrow \infty} \xi_{t}>0$ under which we get that $\sum_{t=1}^{+\infty} Q_{t}<\infty .{ }^{15}$ Since the output is uniformly bounded from above, the present value of the aggregate consumption good is finite, i.e.,

$$
\sum_{t=0}^{\infty} Q_{t} Y_{t}<\infty
$$

where $Y_{t}:=F\left(K_{t}\right)+(1-\delta) K_{t}$. Our result is consistent with the following wellknown result (see Kocherlakota (1992), Santos and Woodford (1997), Huang and Werner (2000)): there is no financial bubble if the present value of the aggregate endowment is finite. ${ }^{16}$ However, in Remark 6.3 we will prove that this is only a sufficient condition ruling out financial bubble.

When one of the conditions in Proposition 8 is violated, bubbles may occur (see examples in Sections 6.1 and 6.2).

In the following result, we assume that $f^{i}=1$ for any $i$, i.e., all agents can borrow with maximum level. ${ }^{17}$ In this case we can weaken conditions in Proposition 8: there is no condition on dividends and the productivity $A$ may be greater than $1 .{ }^{18}$

Proposition 9. Assume that $f^{i}=1$ for every $i$ and the production functions are stationary and linear, i.e., $F_{t}(K)=A K$ for every $t$. Then there is no financial bubble and every equilibrium is efficient.

Proof. Since the production function is linear, the zero profit condition is satisfied. By using the same argument in proof of Proposition 8, we have

$$
\sum_{t=0}^{T} Q_{t} c_{i, t}+Q_{T} k_{i, T+1}+Q_{T} \frac{q_{T}}{p_{T}} a_{i, T}=\left(\frac{r_{0}}{p_{0}}+1-\delta\right) k_{i, 0}+\left(\frac{q_{0}}{p_{0}}+\xi_{0}\right) a_{i,-1}<+\infty .
$$

This implies that $\sum_{t=0}^{\infty} Q_{t} c_{i, t}$ exists, and so does $\lim _{t \rightarrow \infty} Q_{t} k_{i, t+1}+Q_{t} \frac{q_{t}}{p_{t}} a_{i, t}$.

According to Remark 4.1, when $f^{i}=1$, the borrowing constraint of agent $i$ at date $t$ is equivalent to $Q_{t} k_{i, t+1}+Q_{t} \frac{q_{t}}{p_{t}} a_{i, t} \geq 0$.

If $\lim _{t \rightarrow \infty} Q_{t} k_{i, t+1}+Q_{t} \frac{q_{t}}{p_{t}} a_{i, t}>0$, there exists $t_{0}$ such that $Q_{t} k_{i, t+1}+Q_{t} \frac{q_{t}}{p_{t}} a_{i, t}>0$ for every $t \geq t_{0}$. Point 2 of Lemma 20 implies that $\frac{Q_{t}}{Q_{t_{0}}}=\frac{S_{i, t}}{S_{i, t_{0}}}$ for every $t \geq t_{0}$. According to point 1 of Lemma 20, we get $\lim _{t \rightarrow \infty} Q_{t} k_{i, t+1}+Q_{t} \frac{q_{t}}{p_{t}} a_{i, t}=0$, contradiction.

\footnotetext{
${ }^{15}$ Because we always have $\sum_{t=1}^{+\infty} Q_{t} \xi_{t} \leq \frac{q_{0}}{p_{0}}<\infty$.

${ }^{16}$ In their frameworks, the present value of the aggregate endowment is finite if and only if the the present value of the aggregate consumption good is finite

${ }^{17}$ Note that a financial bubble may occur if this condition is violate (see Section 6.1.2).

${ }^{18}$ However, we implicitly require that $A$ satisfies Assumption (H5).
} 
Therefore, we have, for every $i, \lim _{t \rightarrow \infty} Q_{t} k_{i, t+1}+Q_{t} \frac{q_{t}}{p_{t}} a_{i, t}=0$. By summing over $i$, we get that

$$
\lim _{t \rightarrow \infty} Q_{t} K_{t+1}+Q_{t} \frac{q_{t}}{p_{t}}=0 .
$$

As a consequence, there is no financial bubble and every equilibrium is efficient.

\subsection{In search of bubbles}

Proposition 8 suggests that bubbles cannot appear in economies where the output, the capital stocks, and dividends are uniformly bounded away from zero and from above. In this section, we give series of examples where bubbles arise. We will focus on the form of technologies and the size of dividends $\left(\xi_{t}\right)$.

Let us denote $I:=\{1,2, \cdots, m\}$. Before presenting examples of equilibrium with bubbles, we give sufficient conditions for a sequence $\left(p_{t}, q_{t}, r_{t},\left(c_{i, t}, k_{i, t+1}, a_{i, t}\right)_{i \in I}, K_{t}\right)_{t}$ to be an equilibrium. The utility may satisfy $u_{i}(0)=-\infty$.

Proposition 10. Assume that $f^{i}=0$ for any $i$.

If a sequence $\left(\left(c_{i, t}, k_{i, t+1}, a_{i, t}, \sigma_{i, t}, \nu_{i, t}\right)_{i \in I}, K_{t}, p_{t}, q_{t}, r_{t}\right)_{t}$ satisfies

(i) $\forall t, \forall i, c_{i, t}>0, k_{i, t+1} \geqslant 0, a_{i, t} \geqslant 0, \sigma_{i, t} \geqslant 0, \nu_{i, t} \geqslant 0$,

$\forall t, K_{t} \geqslant 0, p_{t}=1, q_{t}>0, r_{t}>0$

(ii) First order conditions

$$
\begin{aligned}
\frac{1}{r_{t+1}+1-\delta} & =\frac{\beta_{i} u_{i}^{\prime}\left(c_{i, t+1}\right)}{u_{i}^{\prime}\left(c_{i, t}\right)}+\sigma_{i, t} \\
\frac{q_{t}}{q_{t+1}+\xi_{t+1}} & =\frac{\beta_{i} u_{i}^{\prime}\left(c_{i, t+1}\right)}{u_{i}^{\prime}\left(c_{i, t}\right)}+\nu_{i, t} \\
\sigma_{i, t} k_{i, t+1}=0 \text { and } \nu_{i, t} a_{i, t} & =0
\end{aligned}
$$

(iii) Transversality conditions

$$
\lim _{t \rightarrow \infty} \beta_{i}^{t} u_{i}^{\prime}\left(c_{i, t}\right) k_{i, t+1}=\lim _{t \rightarrow \infty} \beta_{i}^{t} u_{i}^{\prime}\left(c_{i, t}\right) q_{t} a_{i, t}=0 .
$$

(iv) $\forall t, F_{t}\left(K_{t}\right)-r_{t} K_{t}=\max \left\{F_{t}(k)-r_{t} k: k \geqslant 0\right\}$

(v) $c_{i, t}+k_{i, t+1}-(1-\delta) k_{i, t}+q_{t} a_{i, t}=r_{t} k_{i, t}+\left(q_{t}+\xi_{t}\right) a_{i, t-1}+\theta_{t}^{i} \pi_{t}$ where $\pi_{t}=F_{t}\left(K_{t}\right)-r_{t} K_{t}$

(vi) $K_{t}=\sum_{i \in I} k_{i, t}$

(vii) $\sum_{i \in I} a_{i, t}=1$

then the sequence $\left(p_{t}, q_{t}, r_{t},\left(c_{i, t}, k_{i, t+1}, a_{i, t}\right)_{i \in I}, K_{t}\right)_{t}$ is an equilibrium.

Proof. The proof is left to the reader. 
We now present some examples of (non)bubbles for physical asset market and financial asset market as well.

We assume that there are 2 consumers $H$ and $F$

$$
\begin{aligned}
u_{i}(c) & =\ln (c), \beta_{i}=\beta \in(0,1), f^{i}=0 \quad \forall i=\{H, F\} \\
\delta & \in(0,1) .
\end{aligned}
$$

Their initial endowments are respectively $k_{H, 0}=0, a_{H,-1}=0, k_{F, 0}>0, a_{F,-1}=1$.. Their shares of the profits are

$$
\text { For } \begin{aligned}
t \geq 0, \theta_{2 t}^{H} & =1, \theta_{2 t+1}^{H}=0 \\
\theta_{2 t}^{F} & =0, \theta_{2 t+1}^{F}=1 .
\end{aligned}
$$

The production functions are

$$
F_{t}(K)=a_{t} K+b
$$

where $a_{t}, b>0$ and $\beta\left(1-\delta+a_{t}\right) \leq 1$ for any $t$. Note that $\pi_{t}=b$ for any $t$. Recall that we assume that labor supply is exogenous. Hence, this production function corresponds to the production function $F_{t}(K, L)=a_{t} K+b L$ when labor is taken into account. When the exogenous labor supply is 1 then we come back to (33).

Allocations of the consumer $H$ :

$$
\begin{aligned}
k_{H, 2 t} & =0, a_{H, 2 t-1}=0 \\
c_{H, 2 t-1} & =\left(1-\delta+r_{2 t-1}\right) K_{2 t-1}+q_{2 t-1}+\xi_{2 t-1} \\
k_{H, 2 t+1} & =K_{2 t}, a_{H, 2 t}=1 \\
c_{H, 2 t} & =\pi_{2 t}-K_{2 t+1}-q_{2 t}
\end{aligned}
$$

Allocations of the consumer $F$ :

$$
\begin{aligned}
k_{F, 2 t} & =K_{2 t}, a_{F, 2 t}=1 \\
c_{F, 2 t-1} & =\pi_{2 t-1}-K_{2 t}-q_{2 t-1} \\
k_{F, 2 t+1} & =0, a_{F, 2 t}=0 \\
c_{F, 2 t} & =\left(1-\delta+r_{2 t}\right) K_{2 t}+q_{2 t}+\xi_{2 t} .
\end{aligned}
$$

Prices and the aggregate capital: for any $t, p_{t}=1, r_{t}=a_{t}$, and

$$
\begin{aligned}
K_{t+1}+q_{t} & =\frac{\beta}{1+\beta} b \\
q_{t+1}+\xi_{t+1} & =q_{t}\left(a_{t+1}+1-\delta\right) \\
q_{t}, K_{t} & >0
\end{aligned}
$$

We prove in Appendix 8.4 that this sequence of allocations and prices is an equilibrium. 


\subsubsection{No bubbles}

Let $a_{t}=\delta$ for any $t$.

Let $\left(\xi_{t}\right)$ be such that $\sum_{t=1}^{\infty} \xi_{t}=f<\frac{\beta}{1+\beta} b$. Let us define financial asset prices by

$$
\begin{aligned}
& q_{0}:=f \\
& q_{t}:=f-\sum_{s=1}^{t} \xi_{s}
\end{aligned}
$$

and the aggregate capital by $K_{t+1}:=\frac{\beta}{1+\beta} b-q_{t}$.

We have $\sum_{t} \rho_{t}=\sum_{t} a_{t}=\infty$. Therefore there is no physical capital bubble.

Financial bubble is ruled out because $q_{0}=\sum_{t=1}^{\infty} \xi_{t}=\sum_{t=1}^{\infty} Q_{t} \xi_{t}$.

\subsubsection{Financial bubble without physical bubble}

Let $a_{t}=\delta$ for any $t .\left(\xi_{t}\right)$ such that $\sum_{t=1}^{\infty} \xi_{t}=f<\frac{\beta}{1+\beta} b$.

Let us define $q_{0} \in\left(f, \frac{\beta}{1+\beta} b\right)$ and $q_{t}:=q_{0}-\sum_{s=1}^{t} \xi_{s}$ and $K_{t+1}:=\frac{\beta}{1+\beta} b-q_{t}$.

In this case, physical bubble is ruled out but there is financial bubble since $q_{0}>$ $f=\sum_{t=1}^{\infty} Q_{t} \xi_{t}$. Moreover, there is a continuum of bubble prices $q_{0}$.

Remark 6.2. In this example of financial bubble, the technology is stationary but we require two conditions:

1. $\sum_{t=1}^{\infty} \xi_{t}<\frac{\beta}{1+\beta} b$, which implies that the condition $\liminf _{t \rightarrow \infty} \xi_{t}>0$ in Proposition 8 is not satisfied.

2. $f^{i}=0$ for any $i$. This means that the condition $f^{i}=1$ for any $i$, as required in Proposition 9, is not satisfied.

Remark 6.3. When $a_{t}=\delta$, we see that $Q_{t}=1$ for any $t$ and therefore

$$
\sum_{t=0}^{\infty} Q_{t}\left(F_{t}\left(K_{t}\right)+(1-\delta) K_{t}\right) \geq \sum_{t=0}^{\infty} Q_{t} b=\infty .
$$

Hence the present value of output is infinite in both cases: non financial bubble (Section 6.1.1) and financial bubble (Section 6.1.2). Therefore the fact that the present value of output is finite is only a sufficient condition ruling out financial bubble. 


\subsubsection{Physical bubble without financial bubble}

Let $\left(a_{t}\right)$ be such that $\sum_{t=1}^{\infty} a_{t}<\infty$ then there exists physical bubble. We choose $\left(\xi_{t}\right)$ such that

$$
\sum_{s=1}^{\infty} \frac{\xi_{s}}{\left(1-\delta+a_{1}\right) \cdots\left(1-\delta+a_{s}\right)}=f_{v}<\frac{\beta}{1+\beta} b .
$$

We then choose $q_{0}=f_{v}$ and $\left(q_{t}\right)$ by

$$
q_{0}=\sum_{s=1}^{t} \frac{\xi_{s}}{\left(1-\delta+a_{1}\right) \cdots\left(1-\delta+a_{s}\right)}+\frac{q_{t}}{\left(1-\delta+a_{1}\right) \cdots\left(1-\delta+a_{t}\right)}
$$

In this case, there exists no financial bubble.

\subsubsection{Both assets have bubbles}

Let $\left(a_{t}\right)$ be such that $\sum_{t=1}^{\infty} a_{t}<\infty$ then there exists physical bubble. We choose $\left(\xi_{t}\right)$ such that

$$
\sum_{s=1}^{\infty} \frac{\xi_{s}}{\left(1-\delta+a_{1}\right) \cdots\left(1-\delta+a_{s}\right)}=f_{v}<\frac{\beta}{1+\beta} b
$$

We then choose $q_{0}>f_{v}$ and $\left(q_{t}\right)$ by

$$
q_{0}=\sum_{s=1}^{t} \frac{\xi_{s}}{\left(1-\delta+a_{1}\right) \cdots\left(1-\delta+a_{s}\right)}+\frac{q_{t}}{\left(1-\delta+a_{1}\right) \cdots\left(1-\delta+a_{t}\right)}
$$

Then there exists a financial bubble.

\subsection{On the connections between the absence of bubbles and the fact that $\left(Q_{t}\right) \in l^{1}$}

In Gilles and LeRoy (1992), for a sequence of dividends $\xi=\left(\xi_{t}\right)_{t} \in l^{\infty}$-the space of bounded sequences., and a linear function $P=\left(P_{t}\right) \in l^{1}$, they define the fundamental value of a long-lived asset with dividend $\left(\xi_{t}\right)$ as $\sum_{t=1}^{\infty} P_{t} \xi_{t}$. In particular, $\left(P_{t}\right)$ does not depend on $\left(\xi_{t}\right)$.

Our approach differs from Gilles and LeRoy (1992) on the following points:

1. We do not require that $\left(\xi_{t}\right) \in l^{\infty}$. Instead, $\xi_{t}$ may tend to infinity when $t$ tends to infinity. 
2. The discount factors $\left(Q_{t}\right)$ in our framework endogenously depend on dividends $\xi=\left(\xi_{t}\right)_{t} \cdot{ }^{19}$

3. Since $\left(Q_{t}\right)$ is endogenous, we do not know whether $\left(Q_{t}\right) \in l^{1} .^{20}$

It would be interesting to study the connections between the absence of bubbles and the fact that $\left(Q_{t}\right) \in l^{1}$.

First, on the physical bubble we have

Proposition 11. If $\left(Q_{t}\right) \in l^{1}$ then there is no physical bubble.

Proof. If there is a physical bubble, we have, according to Proposition $6, \sum_{t=1}^{\infty} \rho_{t}<$ $+\infty$. Therefore there exists $t_{0}>1$ and $\rho \in(0, \delta)$ such that $\rho_{t}<\rho$ for any $t \geq t_{0}$. As a consequence we get that

$$
\begin{aligned}
\sum_{t=1}^{\infty} Q_{t} & =\frac{1}{\prod_{s=1}^{t_{0}-1}\left(1-\delta+\rho_{s}\right)} \sum_{t \geq t_{0}} \frac{1}{\left(1-\delta+\rho_{t_{0}}\right) \cdots\left(1-\delta+\rho_{t}\right)} \\
& \geq \frac{1}{\prod_{s=1}^{t_{0}-1}\left(1-\delta+\rho_{s}\right)} \sum_{t \geq t_{0}} \frac{1}{(1-\delta+\rho)^{t}}
\end{aligned}
$$

Since $1-\delta+\rho<1$, we obtain that $\left(Q_{t}\right) \notin l^{1}$.

The converse of this proposition is not true. Indeed, we consider the example as in Section 6.1.1 where $a_{t}=\delta>0$. In this case $\left(Q_{t}\right)=(1,1, \ldots, 1) \notin l^{1}$. However there is no financial bubble.

We now consider the connections between the existence of financial bubble and the fact that $\left(Q_{t}\right) \in l^{1}$. In the case where the output is uniformly bounded from above, according to the proof of Proposition 8, we have: if $\left(Q_{t}\right) \in l^{1}$ then financial bubble is ruled out. However, the inverse sense is not true. Indeed, in the example in Section 6.1.1 we see that financial bubble is ruled out but $\left(Q_{t}\right) \notin l^{1}$ since $Q_{t}=1$ for any $t$.

In what follows we will show that when the output is not uniformly bounded from above, $\left(Q_{t}\right) \in l^{1}$ does not imply that financial bubble is ruled out.

Let us consider the production function as follows

$$
F_{t}(K)=a K+b^{t}
$$

\footnotetext{
${ }^{19}$ Indeed, if $\left(Q_{t}\right)$ do not depend on $\xi=\left(\xi_{t}\right)_{t}$ then so do the expected returns $\left(\rho_{t}\right)$ and the sum $\sum_{t=1}^{\infty} \rho_{t}$. However, according to Example 2 we see that $\sum_{t=1}^{\infty} \rho_{t}<\infty$ if $\xi_{t+1}<\frac{(\beta(1-\delta))^{\frac{1}{\sigma}}}{m} \xi_{t}$ for any $t$. According to condition (30), there is no physical bubble (equivalently $\sum_{t=1}^{\infty} \rho_{t}=\infty$ ) if $\xi_{t}=\xi>0$ for any $t$. These two observations show that the sum $\sum_{t=1}^{\infty} \rho_{t}$ depends on $\xi=\left(\xi_{t}\right)_{t}$, contradiction!

${ }^{20}$ However, according to the fact that $\sum_{t=1}^{\infty} Q_{t} \xi_{t} \leq \frac{q_{0}}{p_{0}}<\infty$, we have $\left(Q_{t}\right) \in l^{1}$ if $\liminf _{t \rightarrow \infty} \xi_{t}>0$.
} 
where $a>\delta$ and $b>1-\delta+a$. In this case we see that $\pi_{t}=b^{t}$ tends to infinity when $t$ tends to infinity.

As Section 6.1 there are two consumers $\mathrm{H}$ and $\mathrm{F}$ whose allocations are given as follows.

Allocations of the consumer $H$ :

$$
\begin{aligned}
k_{H, 2 t} & =0, a_{H, 2 t-1}=0 \\
c_{H, 2 t-1} & =\left(1-\delta+r_{2 t-1}\right) K_{2 t-1}+q_{2 t-1}+\xi_{2 t-1} \\
k_{H, 2 t+1} & =K_{2 t}, a_{h, 2 t}=1 \\
c_{H, 2 t} & =\pi_{2 t}-K_{2 t+1}-q_{2 t}
\end{aligned}
$$

Allocations of the consumer $F$ :

$$
\begin{aligned}
k_{F, 2 t} & =K_{2 t}, a_{F, 2 t}=1 \\
c_{F, 2 t-1} & =\pi_{2 t-1}-K_{2 t}-q_{2 t-1} \\
k_{F, 2 t+1} & =0, a_{F, 2 t}=0 \\
c_{F, 2 t} & =\left(1-\delta+r_{2 t}\right) K_{2 t}+q_{2 t}+\xi_{2 t} .
\end{aligned}
$$

We assume that $b>1>\beta(1-\delta+a)$ and

$$
\frac{\beta}{1+\beta}>\sum_{t=1}^{\infty} \frac{\xi_{t}}{(1-\delta+a)^{t}}=: F_{v} .
$$
by

We choose $q_{0} \in\left[F_{v}, \frac{\beta}{1+\beta}\right)$, and $p_{t}=1, r_{t}=a_{t}$ for any $t \geq 0 .\left(K_{t}, q_{t}\right)_{t \geq 1}$ are given

$$
\begin{aligned}
K_{t+1}+q_{t} & =\frac{\beta}{1+\beta} \pi_{t}=\frac{\beta}{1+\beta} b^{t} \\
q_{t+1}+\xi_{t+1} & =q_{t}\left(a_{t+1}+1-\delta\right) .
\end{aligned}
$$

It means that $q_{t}=(1-\delta+a)^{t}\left(q_{0}-\sum_{s=1}^{t} \frac{\xi_{s}}{(1-\delta+a)^{s}}\right)$. We see that $q_{t}>0$ and $q_{t}<$ $q_{0}(1-\delta+a)^{t}<\frac{\beta}{1+\beta} b^{t}$. Hence $K_{t+1}=\frac{\beta}{1+\beta} b^{t}-q_{t}>0$.

We can verify that the above sequence of prices and allocations is an equilibrium.

We have that $Q_{t}=\frac{1}{(1-\delta+a)^{t}}$ then $\left(Q_{t}\right) \in l^{1}$.

When we choose $q_{0}>F_{v}$ then there exists financial bubble. But if we choose $q_{0}=F_{v}$ then there is no financial bubble. In both cases we always have $\left(Q_{t}\right) \in l^{1}$. It means that $\left(Q_{t}\right) \in l^{1}$ does not rule out financial bubble.

\section{Conclusion}

We build an infinite-horizon dynamic deterministic general equilibrium model in which heterogeneous agents invest in capital and/or financial asset, and consume. We proved the existence of intertemporal equilibrium in this model, even if aggregate capital is not uniformly bounded and technologies are not stationary. 
By using this framework, we studied the relationship between the financial market and the productive sector: when productivity is high enough, the economy will produce at any period; when productivity is low and financial dividends are bounded away from zero, the productive sector will produce nothing at infinitely many dates; in some cases, dividends would be used for the purchase of the physical capital to produce.

We pointed out impacts of the financial asset. Fluctuations on financial dividends $\left(\xi_{t}\right)$ can create fluctuations on the aggregate capital path $\left(K_{t}\right)$. However, if financial dividends are bounded away from zero and capital stocks are uniformly bounded, every equilibrium is efficient and there exist neither bubble on the financial asset market nor on the physical asset market.

We found out the nature of physical and financial bubbles. Physical bubble exists if and only if the sum (over time) of expected capital returns is finite. Financial bubble exists if and only if the sum (over time) of interest rate (in term of financial asset) is finite. The condition that the present value of output is finite is only a sufficient condition ruling out financial bubble. We give series of examples for both physical and financial bubbles/no-bubbles.

\section{Appendix}

\subsection{Existence of equilibrium for truncated bounded econ- omy}

We define the bounded economy $\mathcal{E}_{b}^{T}$ as $\mathcal{E}^{T}$ but all variables (consumption demand, capital supply, asset investment, capital demand) are bounded.

$$
\begin{aligned}
\mathcal{C}_{i} & :=\left[0, B_{c}\right]^{T+1}, \quad B_{c}>1+\max _{t \leq T} F_{t}\left(B_{K}\right)+(1-\delta) B_{k}+\max _{t \leq T} \xi_{t}, \\
\mathcal{K}_{i} & :=\left[0, B_{k}\right]^{T}, \quad B_{k}>D^{T}:=1+\max _{t \leq T} D_{t}\left(K_{0}, \xi_{0}, \ldots, \xi_{t}\right) \\
\mathcal{A}_{i} & :=\left[-B_{a}, B_{a}\right]^{T}, \quad B_{a}>1+B \\
\mathcal{K} & :=\left[0, B_{K}\right]^{T+1}, \quad B_{K}>1+m B_{k},
\end{aligned}
$$

where $B$ such that $B>\max \left\{\max _{t \leq T} \frac{D_{t}}{\xi_{t}}, 1+m \max _{t \leq T} \frac{D_{t}}{\xi_{t}}\right\}$.

$$
\text { Denote } \Delta:=\left\{z_{0}=(p, q, r): 0 \leq p_{t}, q_{t}, r_{t} \leq 1, p_{t}+q_{t}+r_{t}=1 \quad \forall t=0, \ldots, T\right\} .
$$

\subsubsection{Existence of equilibrium for $\epsilon$-economy}

For each $\epsilon>0$ such that $2 m \epsilon<1$, we define $\epsilon$-economy $\mathcal{E}_{b}^{T, \epsilon}$ by adding $\epsilon$ units of each good (consumption good, physical capital, and financial asset) for each agent at date 0 . In the economy $\mathcal{E}_{b}^{T, \epsilon}$, each agent has strictly positive endowment in each 
good. More precisely, the feasible set of agent $i$ is given by

$$
\begin{aligned}
& C_{i}^{T, \epsilon}(p, q, r):=\left\{\left(c_{i, t}, k_{i, t+1}, a_{i, t}\right)_{t=0}^{T} \in \mathbb{R}_{+}^{T+1} \times \mathbb{R}_{+}^{T+1} \times \mathbb{R}_{+}^{T+1}:(\mathrm{a}) k_{i, T+1}, a_{i, T}=0,\right. \\
& \text { (b) } p_{0}\left(c_{i, 0}+k_{i, 1}-(1-\delta)\left(k_{i, 0}+\epsilon\right)\right)+q_{0} a_{i, 0} \\
& \quad \leq p_{0} \epsilon+r_{0}\left(k_{i, 0}+\epsilon\right)+\left(q_{0}+p_{0} \xi_{0}\right)\left(a_{i, t-1}+\epsilon\right)+\theta^{i} \pi_{0} \\
& \text { (c) for each } 1 \leq t \leq T: \\
& 0 \leq\left(q_{t}+p_{t} \xi_{t}\right) a_{i, t-1}+f^{i}\left(r_{t}+(1-\delta) p_{t}\right) k_{i, t} \\
& \left.\quad p_{t}\left(c_{i, t}+k_{i, t+1}-(1-\delta) k_{i, t}\right)+q_{t} a_{i, t} \leq\left(q_{t}+p_{t} \xi_{t}\right) a_{i, t-1}+r_{t} k_{i, t}+\theta^{i} \pi_{t}\right\} .
\end{aligned}
$$

We also define $B_{i}^{T, \epsilon}(p, q, r)$ as follows.

$$
\begin{gathered}
B_{i}^{T, \epsilon}(p, q, r):=\left\{\left(c_{i, t}, k_{i, t+1}, a_{i, t}\right)_{t=0}^{T} \in \mathbb{R}_{+}^{T+1} \times \mathbb{R}_{+}^{T+1} \times \mathbb{R}_{+}^{T+1}:(\mathrm{a}) k_{i, T+1}, a_{i, T}=0\right. \\
\text { (b) } p_{0}\left(c_{i, 0}+k_{i, 1}-(1-\delta)\left(k_{i, 0}+\epsilon\right)\right)+q_{0} a_{i, 0} \\
<p_{0} \epsilon+r_{0}\left(k_{i, 0}+\epsilon\right)+\left(q_{0}+p_{0} \xi_{0}\right)\left(a_{i, t-1}+\epsilon\right)+\theta^{i} \pi_{0}
\end{gathered}
$$

(c) for each $1 \leq t \leq T$ :

$$
\begin{aligned}
& 0<\left(q_{t}+p_{t} \xi_{t}\right) a_{i, t-1}+f^{i}\left(r_{t}+(1-\delta) p_{t}\right) k_{i, t} \\
& \left.p_{t}\left(c_{i, t}+k_{i, t+1}-(1-\delta) k_{i, t}\right)+q_{t} a_{i, t}<\left(q_{t}+p_{t} \xi_{t}\right) a_{i, t-1}+r_{t} k_{i, t}+\theta^{i} \pi_{t}\right\} .
\end{aligned}
$$

We write $C_{i}^{T}(p, q, r), B_{i}^{T}(p, q, r)$ instead of $C_{i}^{T, 0}(p, q, r), B_{i}^{T, 0}(p, q, r)$.

Definition 10. A sequence of prices and quantities $\left(\bar{p}_{t}, \bar{q}_{t}, \bar{r}_{t},\left(\bar{c}_{i, t}, \bar{k}_{i, t+1}, \bar{a}_{i, t}\right)_{i=1}^{m}, \bar{K}_{t}\right)_{t=0}^{T}$ is an equilibrium of the economy $\mathcal{E}_{b}^{T, \epsilon}$ if the following conditions are satisfied:

(i) Price positivity: $\bar{p}_{t}, \bar{r}_{t}, \bar{q}_{t}>0$ for $t \geq 0$.

(ii) All markets clear:

Consumption good

$$
\begin{aligned}
\sum_{i=1}^{m}\left(\bar{c}_{i, 0}+\bar{k}_{i, 1}-(1-\delta)\left(\bar{k}_{i, 0}+\epsilon\right)\right) & =2 m \epsilon+F_{0}\left(\bar{K}_{0}\right)+\xi_{0} \\
\sum_{i=1}^{m}\left(\bar{c}_{i, t}+\bar{k}_{i, t+1}-(1-\delta) \bar{k}_{i, t}\right) & =F_{t}\left(\bar{K}_{t}\right)+\xi_{t}
\end{aligned}
$$

Physical capital

$$
\bar{K}_{0}=\sum_{i=1}^{m}\left(\bar{k}_{i, 0}+\epsilon\right), \quad \bar{K}_{t}=\sum_{i=1}^{m} \bar{k}_{i, t}
$$

Financial asset

$$
\sum_{i=1}^{m} \bar{a}_{i, 0}=\sum_{i=1}^{m}\left(\bar{a}_{i,-1}+\epsilon\right), \quad \sum_{i=1}^{m} \bar{a}_{i, t+1}=\sum_{i=1}^{m} \bar{a}_{i, t} .
$$


(iii) Optimal consumption plans: for each $i,\left(\bar{c}_{i, t}, \bar{k}_{i, t+1}, \bar{a}_{i, t}\right)_{t=0}^{\infty}$ is a solution of the maximization problem of agent $i$ with the feasible set $C_{i}^{T, \epsilon}(p, q, r)$.

(iv) Optimal production plan: for each $t \geq 0,\left(\bar{K}_{t}\right)$ is a solution of the problem $\left(P\left(\bar{p}_{t}, \bar{r}_{t}\right)\right)$.

Lemma 8. $B_{i}^{T, \epsilon}(p, q, r) \neq \emptyset$ and $\bar{B}_{i}^{T, \epsilon}(p, q, r)=C_{i}^{T, \epsilon}(p, q, r)$.

Proof. We rewrite

$$
\begin{aligned}
B_{i}^{T, \epsilon}(p, q, r) & :=\left\{\left(c_{i, t}, k_{i, t+1}, a_{i, t}\right)_{t=0}^{T} \in \mathbb{R}_{+}^{T+1} \times \mathbb{R}_{+}^{T+1} \times \mathbb{R}_{+}^{T+1}: k_{i, T+1}, a_{i, T}=0,\right. \\
0 & <p_{0}\left(\epsilon+(1-\delta)\left(k_{i, 0}+\epsilon\right)+\xi_{0}\left(a_{i, t-1}+\epsilon\right)-c_{i, 0}-k_{i, 1}\right) \\
& +r_{0}\left(k_{i, 0}+\epsilon\right)+\bar{q}_{0}\left(a_{i, t-1}+\epsilon-a_{i, 0}\right)+\theta^{i} \pi_{0} \\
& \text { and for each } 1 \leq t \leq T: \\
& 0<q_{t} a_{i, t-1}+f^{i} \bar{r}_{t} k_{i, t}+p_{t}\left(\xi_{t} a_{i, t-1}+f^{i}(1-\delta) k_{i, t}\right) \\
0 & <p_{t}\left((1-\delta) k_{i, t}+\xi_{t} a_{i, t-1}-c_{i, t}-k_{i, t+1}\right)+r_{t} k_{i, t}+\bar{q}_{t}\left(a_{i, t-1}-a_{i, t}\right)+\theta^{i} \pi_{t} .
\end{aligned}
$$

Since $\epsilon, k_{i, 0}+\epsilon, a_{i, t-1}+\epsilon>0$, we can choose $c_{i, 0} \in\left(0, B_{c}\right), k_{i, 1} \in\left(0, B_{k}\right)$, and $a_{i, 0} \in\left(0, B_{a}\right)$ such that

$$
\begin{aligned}
0 & <p_{0}\left(\epsilon+(1-\delta)\left(k_{i, 0}+\epsilon\right)+\xi_{0}\left(a_{i, t-1}+\epsilon\right)-c_{i, 0}-k_{i, 1}\right) \\
& +r_{0}\left(k_{i, 0}+\epsilon\right)+\bar{q}_{0}\left(a_{i, t-1}+\epsilon-a_{i, 0}\right)+\theta^{i} \pi_{0} .
\end{aligned}
$$

By induction, we see that $B_{i}(p, q, r)$ is not empty.

Remark 8.1. When $\epsilon=0, B_{i}^{T, \epsilon}(p, q, r)$ is empty when $p_{0}=r_{0}=0, p_{1}=r_{1}=0$, and $a_{i,-1}=0$. That's why we need to introduce $\mathcal{E}_{b}^{T, \epsilon}$.

Lemma 9. $B_{i}(p, q, r)$ is lower semi-continuous correspondence on $\Delta . C_{i}(p, q, r)$ is upper semi-continuous on $\Delta$ with compact convex values.

Proof. Clearly, since $B_{i}(p, q, r)$ is non-empty and has open graph.

We define $\Phi:=\Delta \times \prod_{i=1}^{m}\left(\mathcal{C}_{i} \times \mathcal{K}_{i} \times \mathcal{A}_{i}\right) \times \mathcal{K}$. An element $z \in \Phi$ is in the form $z=$ $\left(z_{i}\right)_{i=0}^{m+1}$ where $z_{0}:=(p, q, r), z_{i}:=\left(c_{i}, k_{i}, a_{i}\right)$ for each $i=1, \ldots, m$, and $z_{m+1}=(K)$. 
We now define correspondences. First, we define $\varphi_{0}$ (for additional agent 0 )

$$
\begin{aligned}
& \varphi_{0}: \prod_{i=1}^{m}\left(\mathcal{C}_{i} \times \mathcal{K}_{i} \times \mathcal{A}_{i}\right) \times \mathcal{K} \rightarrow 2^{\Delta} \\
& \varphi_{0}\left(\left(z_{i}\right)_{i=1}^{m+1}\right):=\underset{(p, q, r) \in \Delta}{\arg \max }\left\{p_{0}\left(\sum_{i=1}^{m}\left(c_{i, 0}+k_{i, 1}-(1-\delta)\left(k_{i, 0}+\epsilon\right)-m \epsilon-F_{0}\left(K_{0}\right)-\xi_{0}\right)\right)\right. \\
&+q_{0} \sum_{i=1}^{m}\left(a_{i, 0}-a_{i,-1}-\epsilon\right)+r_{0}\left(K_{0}-\sum_{i=1}^{m}\left(k_{i, 0}+\epsilon\right)\right) \\
&+\sum_{t=1}^{T} p_{t}\left(\sum_{i=1}^{m}\left(c_{i, t}+k_{i, t+1}-(1-\delta) k_{i, t}-F_{t}\left(K_{t}\right)-\xi_{t}\right)\right. \\
&\left.\sum_{t=0}^{T} r_{t}\left(K_{t}-\sum_{i=1}^{m} k_{i, t}\right)+\sum_{t=1}^{T-1} q_{t} \sum_{i=1}^{m}\left(a_{i, t}-a_{i, t-1}\right)\right\} .
\end{aligned}
$$

For each $i=1, \ldots, m$, we define

$$
\begin{aligned}
\varphi_{i}: & \Delta \rightarrow 2^{\mathcal{C}_{i} \times \mathcal{K}_{i} \times \mathcal{A}_{i}} \\
\varphi_{i}((p, q, r)):= & \underset{\left(c_{i}, k_{i}, a_{i}\right) \in C_{i}(p, q, r)}{\arg \max }\left\{\sum_{t=0}^{T} \beta_{i}^{t} u_{i}\left(c_{i, t}\right)\right\} .
\end{aligned}
$$

For each $i=m+1$, we define

$$
\begin{aligned}
\varphi_{m+1}: & \Delta \rightarrow 2^{\mathcal{K}} \\
\varphi_{i}((p, q, r)):= & \underset{(K) \in \mathcal{K}}{\arg \max }\left\{\sum_{t=0}^{T} p_{t} F_{t}\left(K_{t}\right)-r_{t} K_{t}\right\} .
\end{aligned}
$$

Lemma 10. The correspondence $\varphi_{i}$ is lower semi-continuous and non-empty, convex, compact valued for each $i=0,1, \ldots, m+1$.

Proof. This is a direct consequence of the Maximum Theorem.

According to the Kakutani Theorem, there exists $\left(\bar{p}, \bar{q}, \bar{r},\left(\bar{c}_{i}, \bar{k}_{i}, \bar{a}_{i}\right)_{i=1}^{m}\right), K$ such that

$$
\begin{aligned}
(\bar{p}, \bar{q}, \bar{r}) & \in \varphi_{0}\left(\left(\bar{c}_{i}, \bar{k}_{i}, \bar{a}_{i}\right)_{i=1}^{m}\right) \\
\left(\bar{c}_{i}, \bar{k}_{i}, \bar{a}_{i}\right) & \in \varphi_{i}((\bar{p}, \bar{q}, \bar{r})) \\
(K) & \in \varphi_{m+1}((\bar{p}, \bar{q}, \bar{r})) .
\end{aligned}
$$


Denote

$$
\begin{aligned}
& \bar{X}_{0}:=\sum_{i=1}^{m}\left(c_{i, 0}+k_{i, 1}-(1-\delta)\left(k_{i, 0}+\epsilon\right)-F_{0}\left(K_{0}\right)-\xi_{0}\right) \\
& \bar{X}_{t}:=\sum_{i=1}^{m}\left(c_{i, t}+k_{i, t+1}-(1-\delta) k_{i, t}-F_{t}\left(K_{t}\right)\right), \quad t \geq 1 \\
& \bar{Y}_{0}=\bar{K}_{0}-\sum_{i=1}^{m}\left(\bar{k}_{i, 0}+\epsilon\right), \quad \bar{Y}_{t}=\bar{K}_{t}-\sum_{i=1}^{m} \bar{k}_{i, t}, \quad t \geq 1 \\
& \bar{Z}_{0}=\sum_{i=1}^{m}\left(\bar{a}_{i, 0}-\epsilon-\bar{a}_{i,-1}\right), \quad \bar{Z}_{t}=\sum_{i=1}^{m}\left(\bar{a}_{i, t}-\bar{a}_{i, t-1}\right), \quad t \geq 1 .
\end{aligned}
$$

For every $(p, q, r) \in \Delta$, we have

$$
\sum_{t=0}^{T}\left(p_{t}-\bar{p}_{t}\right) \bar{X}_{t}+\sum_{t=0}^{T-1}\left(q_{t}-\bar{q}_{t}\right) \bar{Z}_{t}+\sum_{t=0}^{T}\left(r_{t}-\bar{r}_{t}\right) \bar{Y}_{t} \leq 0 .
$$

By summing the budget constraints over $i$, we get that, for each $t$,

$$
\bar{p} \bar{X}_{t}+\bar{q} \bar{Z}_{t}+\bar{r} \bar{Y}_{t} \leq 0
$$

As a consequence, we have, for every $(p, q, r) \in \Delta$,

$$
p_{t} \bar{X}_{t}+q_{t} \bar{Z}_{t}+r_{t} \bar{Y}_{t} \leq \bar{p} \bar{X}_{t}+\bar{q} \bar{Z}_{t}+\bar{r} \bar{Y}_{t} \leq 0
$$

Therefore, we have $\bar{X}_{t}, \bar{Z}_{t}, \bar{Y}_{t} \leq 0$, which mean that

$$
\begin{aligned}
\sum_{i=1}^{m} \bar{c}_{i, 0}+\bar{k}_{i, 1} & \leq m \epsilon+(1-\delta) \sum_{i=1}^{m}\left(\bar{k}_{i, 0}+\epsilon\right)+F_{0}\left(\bar{K}_{0}\right)+\xi_{0} \\
\sum_{i=1}^{m} \bar{c}_{i, t}+\bar{k}_{i, t+1} & \leq(1-\delta) \sum_{i=1}^{m} \bar{k}_{i, t}+F_{t}\left(\bar{K}_{t}\right), \quad t \geq 1 \\
\bar{K}_{0} & \leq \sum_{i=1}^{m}\left(\bar{k}_{i, 0}+\epsilon\right), \quad \bar{K}_{t} \leq \sum_{i=1}^{m} \bar{k}_{i, t}, \quad t \geq 1 \\
\sum_{i=1}^{m} \bar{a}_{i, 0} & \leq \sum_{i=1}^{m}\left(\bar{a}_{i,-1}+\epsilon\right), \quad \sum_{i=1}^{m} \bar{a}_{i, t} \leq \sum_{i=1}^{m} \bar{a}_{i, t-1}, \quad t \geq 1 .
\end{aligned}
$$

Lemma 11. $\bar{p}_{t}, \bar{q}_{t}, \bar{r}_{t}>0$ for $t=0, \ldots, T$.

Proof. If $\bar{p}_{t}=0$, we obtain that $\bar{c}_{i, t}=B_{c}>n+(1-\delta) B_{k}+F_{t}\left(B_{k}\right)+\xi_{t}$. Therefore, we get $\bar{c}_{i, t}+\bar{k}_{i, t+1}>(1-\delta) \sum_{i=1}^{m} \bar{k}_{i, t}+F_{t}\left(\bar{K}_{t}\right)$, contradiction. As a result, $\bar{p}_{t}>0$.

If $\bar{r}_{t}=0$, the optimality of $(\bar{K})$ implies that $K_{t}=B_{K}$. However, we have $\bar{k}_{i, t} \leq B_{k}$ for every $i, t$. Consequently, $\sum_{i=1}^{m} \bar{k}_{i, t} \leq m B_{k}+n<B_{K}=K_{t}$, contradiction to (73). Therefore, we get $\bar{r}_{t}>0$. 
If $\bar{q}_{t}=0$, we have $\bar{a}_{i, t}=B_{a}$ for each $i$. Thus, $\sum_{i=1}^{m} \bar{a}_{i, t} \geq m B_{a}>1+B_{a}$. However, we have $\sum_{i=1}^{m} \bar{a}_{i, t} \leq \sum_{i=1}^{m} \bar{a}_{i,-1}+m \epsilon=1+m \epsilon<1+B_{a}$, contradiction!

Lemma 12. $\bar{X}_{t}=\bar{Z}_{t}=\bar{Y}_{t}=0$.

Proof. Since prices are strictly positive and the utility functions are strictly increasing, all budget constraints are binding. By summing budget constraints (over $i$ ) at date $t$ we have.

$$
\bar{p}_{t} \bar{X}_{t}+\bar{q}_{t} \bar{Z}_{t}+\bar{r}_{t} \bar{Y}_{t}=0
$$

By combining this with the fact that $\bar{X}_{t}, \bar{Z}_{t}, \bar{Y}_{t} \leq 0$, we obtain $\bar{X}_{t}=\bar{Z}_{t}=\bar{Y}_{t}=0$.

The optimalities of $\left(c_{i}, a_{i}, k_{i}\right)$ and $(K)$ are from (63) and (64).

\subsubsection{When $\epsilon$ tends to zero}

We have so far proved that for each $\epsilon_{n}=1 / n>0$, where $n$ is interger number and high enough, there exists an equilibrium, say

$$
\operatorname{equi}(n):=\left(\bar{p}_{t}(n), \bar{q}_{t}(n), \bar{r}_{t}(n),\left(\bar{c}_{i, t}(n), \bar{k}_{i, t}(n), \bar{a}_{i, t}(n)\right)_{i=1}^{m}, \bar{K}_{t}(n)\right)_{t=0}^{T},
$$

for the economy $\mathcal{E}_{b}^{T, \epsilon_{n}}$. Note that $\bar{p}_{t}(n)+\bar{q}_{t}(n)+\bar{r}_{t}(n)=1$, we can assume that ${ }^{21}$

$$
\begin{aligned}
& \left(\bar{p}(n), \bar{q}(n), \bar{r}(n),\left(\bar{c}_{i}(n), \bar{k}_{i}^{T}(n), \bar{a}_{i}(n)\right)_{i=1}^{m}, \bar{K}^{T}(n)\right) \\
& \stackrel{n \rightarrow \infty}{\longrightarrow}\left(\bar{p}, \bar{q}, \bar{r},\left(\bar{c}_{i}, \bar{k}_{i}, \bar{a}_{i}\right)_{i=1}^{m}, \bar{K}\right) .
\end{aligned}
$$

Markets clearing conditions: By taking limit of market clearing conditions for economy $\mathcal{E}_{b}^{T, \epsilon_{n}}$, we obtain market clearing conditions for the economy $\mathcal{E}_{b}^{T}$.

Optimality of $\bar{K}_{t}$ : Take $K \geq 0$. We have $\bar{p}_{t}(n) F_{t}(K)-\bar{r}_{t}(n) K \leq \bar{p}_{t}(n) F_{t}\left(\bar{K}_{t}(n)\right)-$ $\bar{r}_{t}(n) \bar{K}_{t}(n)$. Let $n$ tend to infinity, we obtain that $\bar{p}_{t} F_{t}(K)-\bar{r}_{t} K \leq \bar{p}_{t} F_{t}\left(\bar{K}_{t}\right)-\bar{r}_{t} \bar{K}_{t}$. Therefore, the optimality of $\bar{K}_{t}$ is proved.

Lemma 13. If $\bar{p}_{t}>0$, we have $\bar{r}_{t}>0$ for each $t \geq 0$.

Proof. Assume that $\bar{r}_{t}=0$. According to the optimality of $\bar{K}_{t}$, we have $F_{t}(K) \leq$ $F_{t}(\bar{K})$ for every $K \geq 0$. Then $\bar{K}_{t}=B_{K}>D_{t-1}$. However, according to market clearing condition, we have

$$
\bar{K}_{t+1} \leq(1-\delta) \bar{K}_{t}+F_{t}\left(\bar{K}_{t}\right)+\xi_{t}
$$

As a consequence, $\bar{K}_{t}<D_{t-1}$, contradiction.

\footnotetext{
${ }^{21}$ In fact, since prices and allocations are bounded, there exists a subsequence $\left(n_{1}, n_{2}, \ldots,\right)$ such that equi $\left(n_{s}\right)$ converges. However, without loss of generality, we can assume that equi $(n)$ converges.
} 
Corollary 5. We have $\bar{q}_{t}+\bar{r}_{t}>0$ for each $t \geq 0$.

Lemma 14. We have $\bar{p}_{0}+\bar{q}_{0}>0$.

Proof. If $\bar{p}_{0}+\bar{q}_{0}=0$, we get $\bar{p}_{0}=0, \bar{r}_{0}=1$. According to the optimality of $K_{0}$, we have $K \geq K_{0}$ for every $K \geq 0$. Then, $K_{0}=0$, contradiction.

The following result is very important and allows us to pass to the limit when $\epsilon$ tends to zero. The economic intuition is that if agent $i$ has something on hand, i.e., $a_{i,-1}>0$ or $k_{i, 0}>0$, then the budget constraint of this agent is not empty.

Lemma 15. $B_{i}^{T}(\bar{p}, \bar{q}, \bar{r}) \neq \emptyset$ if $\bar{p}_{0}+\bar{q}_{0}>0, \bar{q}_{t}+\bar{r}_{t}>0$ for each $t \geq 0$, and one of the following condition is satisfied

1. $\bar{q}_{0}=0$.

2. $\bar{q}_{0}>0$ and $a_{i,-1}>0$.

Proof. In the case when $\bar{q}_{0}=0$, we see that $\bar{p}_{0}, \bar{r}_{0}>0$. Since $\left(k_{i, 0}, a_{i,-1}\right) \neq(0,0)$, we can use the same argument in Lemma 8 to prove that $B_{i}^{T}(\bar{p}, \bar{q}, \bar{r}) \neq \emptyset$.

If $\bar{q}_{0}>0$ and $a_{i,-1}>0$, we get $\xi_{0} a_{i,-1}>0 . B_{i}^{T}(\bar{p}, \bar{q}, \bar{r}) \neq \emptyset$ is also proved by using the same argument.

Lemma 16. We have $\bar{p}_{t}, \bar{q}_{t}, \bar{r}_{t}>0$.

Proof. Since $\sum_{i=1}^{m} a_{i,-1}=1>0$, there exists an agent $i$ such that $a_{i,-1}>0$. According to Lemma 15 , we have $B_{i}^{T}(\bar{p}, \bar{q}, \bar{r}) \neq \emptyset$. We are going to prove the optimality of allocation $\left(\bar{c}_{i}, \bar{k}_{i}, \bar{a}_{i}\right)$.

Let $\left(c_{i}, k_{i}, a_{i}\right)$ be a feasible allocation of the maximization problem of agent $i$ with the feasible set $C_{i}^{T}(\bar{p}, \bar{q}, \bar{r})$. We have to prove that $\sum_{t=0}^{\infty} \beta_{i}^{t} u_{i}\left(c_{i, t}\right) \leq \sum_{t=0}^{\infty} \beta_{i}^{t} u_{i}\left(\bar{c}_{i, t}\right)$.

Since $B_{i}^{T}(\bar{p}, \bar{q}, \bar{r}) \neq \emptyset$, there exists $(h)_{h \geq 0}$ and $\left(c_{i}^{h}, k_{i}^{h}, a_{i}^{h}\right) \in B_{i}^{T}(\bar{p}, \bar{q}, \bar{r})$ such that $\left(c_{i}^{h}, k_{i}^{h}, a_{i}^{h}\right)$ converges to $\left(c_{i}, k_{i}, a_{i}\right)$. We have

$$
\begin{aligned}
\bar{p}_{t}\left(c_{i, t}^{h}+k_{i, t+1}^{h}-(1-\delta) k_{i, t}^{h}\right)+\bar{q}_{t} a_{i, t}^{h}<\bar{r}_{t} k_{i, t}^{h}+\left(\bar{q}_{t}+\bar{p}_{t} \xi_{t}\right) a_{i, t-1}^{h}+\theta^{i} \pi_{t} \\
0<\left(\bar{q}_{t}+\bar{p}_{t} \xi_{t}\right) a_{i, t-1}^{h}+f^{i}\left(\bar{r}_{t}+(1-\delta) \bar{p}_{t}\right) k_{i, t}^{h} .
\end{aligned}
$$

Fix $h$. Let $n_{0}$ ( $n_{0}$ depend on $\left.h\right)$ be high enough such that for every $n \geq n_{0}$, $\left(c_{i}^{h}, k_{i}^{h}, a_{i}^{h}\right) \in C_{i}^{T, 1 / n}(\bar{p}(n), \bar{q}(n), \bar{r}(n))$. Therefore, we have $\sum_{t=0}^{\infty} \beta_{i}^{t} u_{i}\left(c_{i, t}^{h}\right) \leq \sum_{t=0}^{\infty} \beta_{i}^{t} u_{i}\left(\bar{c}_{i, t}(n)\right)$.

Let $n$ tend to infinity, we obtain $\sum_{t=0}^{\infty} \beta_{i}^{t} u_{i}\left(c_{i, t}^{h}\right) \leq \sum_{t=0}^{\infty} \beta_{i}^{t} u_{i}\left(\bar{c}_{i, t}\right)$.

Let $h$ tend to infinity, we have $\sum_{t=0}^{\infty} \beta_{i}^{t} u_{i}\left(c_{i, t}\right) \leq \sum_{t=0}^{\infty} \beta_{i}^{t} u_{i}\left(\bar{c}_{i, t}\right)$. It means that we have just proved the optimality of $\left(\bar{c}_{i}, \bar{k}_{i}, \bar{a}_{i}\right)$.

We now prove $\bar{p}_{t}>0$ for every $t$. Indeed, if $\bar{p}_{t}=0$, the optimality of $\left(\bar{c}_{i}, \bar{k}_{i}, \bar{a}_{i}\right)$ implies that $\bar{c}_{i, t}=B_{c}>(1-\delta) \bar{K}_{t}+F_{t}\left(\bar{K}_{t}\right)+\xi_{t}$, contradiction.

Therefore, it is easy to prove that $\bar{q}_{t}>0, \bar{r}_{t}>0$.

Lemma 17. For each $i,\left(\bar{c}_{i}, \bar{k}_{i}, \bar{a}_{i}\right)$ is optimal.

Proof. By using the same argument in Lemma 16. 


\subsection{Existence of equilibrium for truncated unbounded econ- omy}

Proof of Lemma 3 . Let $\left(\bar{p}_{t}, \bar{q}_{t}, \bar{r}_{t},\left(\bar{c}_{i, t}, \bar{k}_{i, t+1}, \bar{a}_{i, t},\right)_{i=1}^{m}, \bar{K}_{t}\right)_{t=0}^{T}$ be an equilibrium of $\mathcal{E}_{b}^{T}$. Note that $k_{i, T+1}=a_{i, T}=0$ for every $i=1, \ldots, m$. We can see that conditions (i) and (ii) in Definition 10 are satisfied. We will show that conditions (iii) and (iv) in Definition 10 are also satisfied.

For Condition (iii), let $z_{i}:=\left(c_{i, t}, k_{i, t+1}, a_{i, t}\right)_{t=0}^{T}$ be a feasible plan of household $i$.

Assume that $\sum_{t=0}^{T} \beta_{i}^{t} u_{i}\left(c_{i, t}\right)>\sum_{t=0}^{T} \beta_{i}^{t} u_{i}\left(\bar{c}_{i, t}\right)$. For each $\gamma \in(0,1)$, we define $z_{i}(\gamma):=$ $\gamma z_{i}+(1-\gamma) \bar{z}_{i}$. By definition of $\mathcal{E}_{b}^{T}$, we can choose $\gamma$ sufficiently close to 0 such that $z_{i}(\gamma) \in \mathcal{C}_{i} \times \mathcal{K}_{i} \times \mathcal{A}_{i}$. It is clear that $z_{i}(\gamma)$ is a feasible allocation.

By the concavity of the utility function, we have

$$
\begin{aligned}
\sum_{t=0}^{T} \beta_{i}^{t} u_{i}\left(c_{i, t}(\gamma)\right) & \geq \gamma \sum_{t=0}^{T} \beta_{i}^{t} u_{i}\left(c_{i, t}\right)+(1-\gamma) \sum_{t=0}^{T} \beta_{i}^{t} u_{i}\left(\bar{c}_{i, t}\right) \\
& >\sum_{t=0}^{T} \beta_{i}^{t} u_{i}\left(\bar{c}_{i, t}\right) .
\end{aligned}
$$

Contradiction to the optimality of $\bar{z}_{i}$. So, we have shown that conditions (iii) in Definition 10 is satisfied. A similar proof for conditions (iv) in Definition 10 permits us to finish our proof.

\subsection{Existence of equilibrium for the infinite horizon economy}

Proof of Theorem 1 . We have shown that for each $T \geq 1$, there exists an equilibrium for the economy $\mathcal{E}^{T}$. We denote $\left(\bar{p}^{T}, \bar{q}^{T}, \bar{r}^{T},\left(\bar{c}_{i}^{T}, \bar{k}_{i}^{T}, \bar{a}_{i}^{T}\right)_{i=1}^{m}, \bar{K}^{T}\right)$ is an equilibrium of $T$ - truncated economy $\mathcal{E}^{T}$.

We can normalize by setting $\bar{p}_{t}^{T}+\bar{q}^{T}+\bar{r}_{t}^{T}=1$ for every $t \leq T$. According to (6), we see that

$$
\begin{aligned}
0<\bar{c}_{i, t}^{T}, \bar{K}_{t}^{T} & \leq D_{t} \\
-\bar{a}_{i, t}^{T} & \leq \frac{D_{t+1}}{\xi_{t+1}}, \quad \sum_{i=1}^{m} \bar{a}_{i, t}^{T}=1 .
\end{aligned}
$$

Therefore, we can assume that

$$
\begin{aligned}
& \left(\bar{p}^{T}, \bar{q}^{T}, \bar{r}^{T},\left(\bar{c}_{i}^{T}, \bar{k}_{i}^{T}, \bar{a}_{i}^{T}\right)_{i=1}^{m}, \bar{K}^{T}\right) \\
& \stackrel{T \rightarrow \infty}{\longrightarrow}\left(\bar{p}, \bar{q}, \bar{r},\left(\bar{c}_{i}, \bar{k}_{i}, \bar{a}_{i}\right)_{i=1}^{m}, \bar{K}\right) \quad \text { (for the product topology ). }
\end{aligned}
$$

It is easy to see that all markets clear, and at each date $t, \bar{K}_{t}$ is a solution of the firm's maximization problem. As in proof of the existence of equilibrium for bounded $T$-truncated economy, we have 
(i) $\bar{r}_{t}>0$ if $\bar{p}_{t}>0$.

(ii) $\bar{r}_{t}+\bar{q}_{t}>0$ for each $t \geq 0$.

(iii) $\bar{p}_{0}+\bar{q}_{0}>0$.

Lemma 18. We have $\bar{p}_{t}>0$ for each $t \geq 0$.

Proof. There exists $i$ such that $a_{i,-1}>0$. By using the same argument in Lemma 15 , we see that $B_{i}^{T}(\bar{p}, \bar{q}, \bar{r}) \neq \emptyset$.

Let $\left(c_{i}, k_{i}, a_{i}\right)$ be a feasible alloation of the problem $P_{i}(\bar{p}, \bar{q}, \bar{r})$. We have to prove that $\sum_{t=0}^{\infty} \beta_{i}^{t} u_{i}\left(c_{i, t}\right) \leq \sum_{t=0}^{\infty} \beta_{i}^{t} u_{i}\left(\bar{c}_{i, t}\right)$. Note that, without loss of generality, we can only consider feasible allocations such that $\bar{p}_{T}\left(c_{i, T}+k_{i, T+1}-(1-\delta) k_{i, t}\right)+\bar{q}_{i, T} a_{i, t} \geq 0$. We define $\left(c_{i, t}^{\prime}, k_{i, t+1}^{\prime}, a_{i, t}^{\prime}\right)_{t=0}^{T}$ as follows:

$$
\begin{aligned}
c_{i, t} & =k_{i, t+1}=a_{i, t}=0 \text { if } t>T \\
a_{i, t}^{\prime} & =a_{i, t}, \text { if } t \leq T-1, a_{i, T}=0 \\
c_{i, t}^{\prime} & =c_{i, t}, \text { if } t \leq T-1, \quad k_{i, t+1}^{\prime}=k_{i, t+1}, \text { if } t \leq T-1 \\
\bar{p}_{T}\left(c_{i, T}^{\prime}+k_{i, T+1}^{\prime}-(1-\delta) k_{i, t}\right) & =\bar{p}_{T}\left(c_{i, T}+k_{i, T+1}-(1-\delta) k_{i, t}\right)+\bar{q}_{i, T} a_{i, t}
\end{aligned}
$$

We see that $\left(c_{i, t}^{\prime}, k_{i, t+1}^{\prime}, a_{i, t}^{\prime}\right)_{t=0}^{T}$ belongs to $C_{i}^{T}(\bar{p}, \bar{q}, \bar{r})$.

Since $B_{i}^{T}(\bar{p}, \bar{q}, \bar{r}) \neq \emptyset$, there exists a sequence $\left(\left(c_{i, t}^{n}, k_{i, t+1}^{n}, a_{i, t}^{n}\right)_{t=0}^{T}\right)_{n=0}^{\infty} \in B_{i}^{T}(\bar{p}, \bar{q}, \bar{r})$ with $k_{i, T+1}^{n}=0, a_{i, T}^{n}=0$, and this sequence converges to $\left(c_{i, t}^{\prime}, k_{i, t+1}^{\prime}, a_{i, t}^{\prime}\right)_{t=0}^{T}$ when $n$ tends to infinity. We have

$$
\bar{p}_{t}\left(c_{i, t}^{n}+k_{i, t+1}^{n}-(1-\delta) k_{i, t}^{n}\right)+\bar{q}_{t} a_{i, t}^{n}<\bar{r}_{t} k_{i, t}^{n}+\left(\bar{q}_{t}+\bar{p}_{t} \xi_{t}\right) a_{i, t-1}^{n}+\theta^{i} \pi_{t}\left(\bar{p}_{t}, \bar{r}_{t}\right)
$$

We can chose $s_{0}$ high enough such that $s_{0}>T$ and for every $s \geq s_{0}$, we have

$$
\bar{p}_{t}^{s}\left(c_{i, t}^{n}+k_{i, t+1}^{n}-(1-\delta) k_{i, t}^{n}\right)+\bar{q}_{t}^{s} a_{i, t}^{n}<\bar{r}_{t}^{s} k_{i, t}^{n}+\left(\bar{q}_{t}^{s}+\bar{p}_{t}^{s} \xi_{t}\right) a_{i, t-1}^{n}+\theta^{i} \pi_{t}\left(\bar{p}_{t}^{s}, \bar{r}_{t}^{s}\right) .
$$

It means that $\left(c_{i, t}^{n}, k_{i, t+1}^{n}, a_{i, t}^{n}\right)_{t=0}^{T} \in C_{i}^{T}\left(\bar{p}^{s}, \bar{q}^{s}, \bar{r}^{s}\right)$. Therefore, we get $\sum_{t=0}^{T} \beta_{i}^{t} u_{i}\left(c_{i, t}^{n}\right) \leq$ $\sum_{t=0}^{s} \beta_{i}^{t} u_{i}\left(\bar{c}_{i, t}^{s}\right)$. Let $s$ tend to infinity, we obtain $\sum_{t=0}^{T} \beta_{i}^{t} u_{i}\left(c_{i, t}^{n}\right) \leq \sum_{t=0}^{\infty} \beta_{i}^{t} u_{i}\left(\bar{c}_{i, t}\right)$.

Let $n$ tend to infinity, we have $\sum_{t=0}^{T} \beta_{i}^{t} u_{i}\left(c_{i, t}^{\prime}\right) \leq \sum_{t=0}^{\infty} \beta_{i}^{t} u_{i}\left(\bar{c}_{i, t}\right)$ for every $T$. As a consequence, we have: for every $T$

$$
\sum_{t=0}^{T-1} \beta_{i}^{t} u_{i}\left(c_{i, t}\right) \leq \sum_{t=0}^{\infty} \beta_{i}^{t} u_{i}\left(\bar{c}_{i, t}\right) .
$$

Let $T$ tend to infinity, we obtain $\sum_{t=0}^{\infty} \beta_{i}^{t} u_{i}\left(c_{i, t}\right) \leq \sum_{t=0}^{\infty} \beta_{i}^{t} u_{i}\left(\bar{c}_{i, t}\right)$.

Therefore, we have proved the optimality of $\left(\bar{c}_{i}, \bar{k}_{i}, \bar{a}_{i}\right)$.

Prices $\bar{p}_{t}, \bar{q}_{t}$ are strictly positive since the utility function of agent $i$ is strictly increasing. $\bar{r}_{t}>0$ is implied by $\bar{p}_{t}>0$. 
Lemma 19. For each $i,\left(\bar{c}_{i}, \bar{k}_{i}, \bar{a}_{i}\right)$ is optimal.

Proof. Since $\bar{p}_{t}, \bar{q}_{t}, \bar{r}_{t}>0$ and $\left(k_{i, 0}, a_{i,-1}\right) \neq(0,0)$, we get that $B_{i}^{T}(\bar{p}, \bar{r}, \bar{q}) \neq \emptyset$. By using the same argument in Lemma 18 , we can prove that $\left(\bar{c}_{i}, \bar{k}_{i}, \bar{a}_{i}\right)$ is optimal.

\subsection{Other formal proofs}

Proof of Remark 3.2. Indeed, assume that there exists $b<\infty$ such that (8) and (9) for every $i$. Denote $A=F^{\prime}(b), B=F(b)$. Since $F(\cdot)$ is increasing and concave, we obtain $F(x) \leq A x+B$ for every $x \geq 0$. Since definition of $D_{t}\left(K_{0}, \xi_{0}, \ldots, \xi_{t}\right)$, we have

$$
\begin{aligned}
D_{t}\left(F, \delta, K_{0}, \xi_{0}, \ldots, \xi_{t}\right) & \leq(A+1-\delta)^{t+1} K_{0}+(A+1-\delta)^{t}\left(B+\xi_{0}\right)+\cdots+\left(B+\xi_{t}\right) \\
& \leq(A+1-\delta)^{t+1} K_{0}+\left(B+\max _{s \leq t}\left\{\xi_{s}\right\}\right) \sum_{s=0}^{t}(A+1-\delta)^{s}
\end{aligned}
$$

Since $u_{i}$ is concave, there exists $a_{i}>0, b_{i}>0$ such that $u_{i}(x) \leq a_{i} x+b_{i}$ for every $x \geq 0$. Then

$$
\sum_{t=0}^{\infty} \beta_{i}^{t} u_{i}\left(D_{t}\left(F, \delta, K_{0}, \xi_{0}, \ldots, \xi_{t}\right)\right) \leq \sum_{t=0}^{\infty} \beta_{i}^{t}\left(a_{i} D_{t}\left(F, \delta, K_{0}, \xi_{0}, \ldots, \xi_{t}\right)+b_{i}\right) .
$$

Case 1: $A \leq \delta$ then $D_{t}\left(F, \delta, K_{0}, \xi_{0}, \ldots, \xi_{t}\right) \leq K_{0}+(t+1)\left(B+\max _{s \leq t} \xi_{s}\right)$. Combining with (8), (9), and (77) we obtain (7).

Case 2: $A>\delta$, then

$$
\begin{aligned}
D_{t}\left(F, \delta, K_{0}, \xi_{0}, \ldots, \xi_{t}\right) & =(A+1-\delta)^{t+1} K_{0}+(A+1-\delta)^{t}\left(B+\xi_{0}\right)+\cdots+\left(B+\xi_{t}\right) \\
& \leq(A+1-\delta)^{t+1} K_{0}+\left(B+\max _{s \leq t}\left\{\xi_{s}\right\}\right) \frac{(A+1-\delta)^{t+1}-1}{A-\delta} .
\end{aligned}
$$

Combining with (8), (9), and (77) we obtain (7).

Proof for Example 1. It is easy to see that all markets clear and the optimal problem of firm is solved.

It is easy to see that all transversality conditions are satisfied. Therefore we have to only check the optimality of household's optimization problem by verifying the FOCs $(10,11,12)$.

FOCs of consumption $\mathrm{n}$ are hold because of the choices of multipliers.

FOCs of $a_{h, t}$ with $h \in\{i, j\}$. We have $\frac{\mu_{h, t+1}}{\mu_{h, t}}=\beta$ for every $t \geq 1$. Since $q_{t}=\xi \frac{\beta}{1-\beta}$ for every $t \geq 1$, we have $\frac{q_{t+1}+\xi}{q_{t}}=\frac{\mu_{h, t+1}}{\mu_{h, t}}$ for every $t \geq 1$. At initial date, we have to prove that $\frac{q_{0}}{q_{1}+\xi}=\frac{\mu_{h, 1}}{\mu_{h, 0}}$, i.e.,

$$
\frac{q_{0}}{\xi}(1-\beta)=\frac{\mu_{h, 1}}{\mu_{h, 0}} .
$$


FOC of $k_{h, t}$ with $h \in\{i, j\}$.

For $t \geq 2$, we have to prove that $\frac{1}{F^{\prime}(0)+1-\delta} \geq \max _{i} \frac{\mu_{i, t+1}}{\mu_{i, t}}$. This is true because $\frac{\mu_{h, t+1}}{\mu_{h, t}}=\beta$ for every $t \geq 1$ and $\beta\left(F^{\prime}(0)+1-\delta\right) \leq 1$.

At date 1, we have to prove that

$$
1 \geq \frac{\mu_{h, 1}}{\mu_{h, 0}}\left(F^{\prime}(0)+1-\delta\right) \quad \forall h \in\{i, j\}
$$

Therefore, we have only to check the following system

$$
\begin{aligned}
& 1 \geq \frac{\mu_{h, 1}}{\mu_{h, 0}}\left(F^{\prime}(0)+1-\delta\right) \quad \forall h \in\{i, j\} . \\
& \frac{q_{0}}{\xi}(1-\beta)=\frac{\mu_{h, 1}}{\mu_{h, 0}}, \quad \forall h \in\{i, j\} .
\end{aligned}
$$

We have

$$
\begin{aligned}
& \frac{\mu_{i, 1}}{\mu_{i, 0}}=\beta \frac{u_{i}^{\prime}(a \xi)}{u_{i}^{\prime}\left(a\left(F\left(K_{0}\right)+(1-\delta) K_{0}+\xi_{0}\right)\right)}=\beta\left(\frac{F\left(K_{0}\right)+(1-\delta) K_{0}+\xi_{0}}{\xi}\right)^{\sigma} \\
& \frac{\mu_{j, 1}^{\prime}}{\mu_{j, 0}}=\beta \frac{u_{j}^{\prime}(a \xi)}{u_{j}^{\prime}\left(a\left(F\left(K_{0}\right)+(1-\delta) K_{0}+\xi_{0}\right)\right)}=\beta\left(\frac{F\left(K_{0}\right)+(1-\delta) K_{0}+\xi_{0}}{\xi}\right)^{\sigma} .
\end{aligned}
$$

Our system becomes

$$
\begin{aligned}
& 1 \geq \beta\left(F^{\prime}(0)+1-\delta\right)\left(\frac{F\left(K_{0}\right)+(1-\delta) K_{0}+\xi_{0}}{\xi}\right)^{\sigma}, \\
& \left(\frac{F\left(K_{0}\right)+(1-\delta) K_{0}+\xi_{0}}{\xi}\right)^{\sigma}=\frac{q_{0}}{\xi} \frac{1-\beta}{\beta} .
\end{aligned}
$$

Choose $\xi, \xi_{0}, k_{0}, q_{0}$ to be satisfied this system.

Proof for Proposition 2. Assume that there exists $t \geq 0, T \geq 1$ such that $\xi_{t} \geq$ $\xi_{t+T}$. If $\left(F^{\prime}(0)+1-\delta\right) \beta_{i}>1$ for every $i=1, \ldots, m$.

If $K_{t+s}=0$ for every $s=1, \ldots, T$, we have

$$
\begin{aligned}
\sum_{i=1}^{m} c_{i, t} & =F\left(K_{t}\right)+(1-\delta) K_{t}+\xi_{t}, \\
\sum_{i=1}^{m} c_{i, t+s}+K_{t+s+1} & =\xi_{t+s}, \quad \forall s=1, \ldots, T .
\end{aligned}
$$

Therefore, we have

$$
\sum_{i=1}^{m} c_{i, t} \geq \xi_{t} \geq \xi_{t+T} \geq \sum_{i=1}^{m} c_{i, t+T}
$$


Consequently, there exists $i \in\{1, \cdots, m\}$ such that $c_{i, t} \geq c_{i, t+T}$, hence $u_{i}^{\prime}\left(c_{i, t+T}\right) \geq$ $u_{i}^{\prime}\left(c_{i, t}\right)$. As a consequence, we have that

$$
\left(\frac{1}{F^{\prime}(0)+1-\delta}\right)^{T} \geq \prod_{s=1}^{T} \max _{j} \frac{\beta_{j} u_{j}^{\prime}\left(c_{j, t+s}\right)}{u_{j}^{\prime}\left(c_{j, t+s-1}\right)} \geq \frac{\beta_{i}^{T} u_{i}^{\prime}\left(c_{i, t+T}\right)}{u_{i}^{\prime}\left(c_{i, t}\right)} \geq\left(\beta_{i}\right)^{T} .
$$

So $1 \geq\left(F^{\prime}(0)+1-\delta\right) \beta_{i}$, contradiction!

Proof for Proposition 3 . Assume that $\beta_{i}\left(F^{\prime}(0)+1-\delta\right) u_{i}^{\prime}\left(\xi_{t+1}\right)>u_{i}^{\prime}\left(\frac{F\left(K_{t}\right)+(1-\delta) K_{t}+\xi_{t}}{m}\right)$ for every $i=1, \ldots, m$.

If $K_{t+1}=0$, the market clearing conditions imply that

$$
\begin{aligned}
\sum_{i=1}^{m} c_{i, t} & =F\left(K_{t}\right)+(1-\delta) K_{t}+\xi_{t} \\
\sum_{i=1}^{m} c_{i, t+1}+K_{t+2} & =\xi_{t+1} .
\end{aligned}
$$

Therefore, there exists $i \in\{1, \ldots, m\}$ such that $c_{i, t} \geq \frac{F\left(K_{t}\right)+(1-\delta) K_{t}+\xi_{t}}{m}$, so $u_{i}^{\prime}\left(c_{i, t}\right) \leq u_{i}^{\prime}\left(\frac{F\left(K_{t}\right)+(1-\delta) K_{t}+\xi_{t}}{m}\right)$.

Moreover, FOC of $K_{t+1}$ implies that $\frac{r_{t+1}}{p_{t+1}} \geq F^{\prime}\left(K_{t+1}\right)=F^{\prime}(0)$. FOC of $k_{i, t+1}$ implies that $\frac{1}{\frac{r_{t+1}}{p_{t+1}}+1-\delta} \geq \max _{j} \frac{\mu_{j, t+1}}{\mu_{j, t}}$. Therefore, we get that

$$
\frac{1}{F^{\prime}(0)+1-\delta} \geq \max _{j} \frac{\beta_{j} u_{j}^{\prime}\left(c_{j, t+1}\right)}{u_{j}^{\prime}\left(c_{j, t}\right)} \geq \frac{\beta_{i} u_{i}^{\prime}\left(c_{i, t+1}\right)}{u_{i}^{\prime}\left(c_{i, t}\right)} \geq \frac{\beta_{i} u_{i}^{\prime}\left(\xi_{t+1}\right)}{u_{i}^{\prime}\left(\frac{F\left(K_{t}\right)+(1-\delta) K_{t}+\xi_{t}}{m}\right)}
$$

contradicting our assumption.

Proof for Proposition 4. Market clearing conditions imply that

$$
\begin{aligned}
\sum_{i=1}^{m} c_{i, t}+K_{t+1} & =F\left(K_{t}\right)+(1-\delta) K_{t}+\xi_{t} \\
\sum_{i=1}^{m} c_{i, t+1}+K_{t+2} & =F\left(K_{t+1}\right)+(1-\delta) K_{t+1}+\xi_{t+1} .
\end{aligned}
$$

Therefore, there exists $i \in\{1, \ldots, m\}$ such that $m c_{i, t}+K_{t+1} \geq \xi_{t}$.

Moreover, we have

$$
\frac{1}{F^{\prime}\left(K_{t+1}\right)+1-\delta} \geq \frac{\beta_{i} u_{i}^{\prime}\left(c_{i, t+1}\right)}{u_{i}^{\prime}\left(c_{i, t}\right)} \geq \frac{\beta_{i} u_{i}^{\prime}\left(F\left(K_{t+1}\right)+(1-\delta) K_{t+1}+\xi_{t+1}\right)}{u_{i}^{\prime}\left(c_{i, t}\right)} .
$$


This can be rewritten as

$$
u_{i}^{\prime}\left(c_{i, t}\right) \geq\left(F^{\prime}\left(K_{t+1}\right)+1-\delta\right) \beta_{i} u_{i}^{\prime}\left(F\left(K_{t+1}\right)+(1-\delta) K_{t+1}+\xi_{t+1}\right)
$$

Hence, we have $c_{i, t} \leq G_{i}\left(K_{t+1}, \xi_{t+1}\right)$, where $G_{i}\left(K_{t+1}, \xi_{t+1}\right)$ is defined by

$$
u_{i}^{\prime}\left(G_{i}\left(K_{t+1}, \xi_{t+1}\right)\right)=\left(F^{\prime}\left(K_{t+1}\right)+1-\delta\right) \beta_{i} u_{i}^{\prime}\left(F\left(K_{t+1}\right)+(1-\delta) K_{t+1}+\xi_{t+1}\right) .
$$

As a result, we obtain

$$
\xi_{t} \leq K_{t+1}+m G_{i}\left(K_{t+1}, \xi_{t+1}\right)
$$

Proof of Proposition 8. We prepare the presentation of our no-bubble results with the following result:

Lemma 20. (1) For each $i$, we define $S_{i, 0}=1, S_{i, t}:=\frac{\beta_{i}^{t} u_{i}^{\prime}\left(c_{i, t}\right)}{u_{i}^{\prime}\left(c_{i, 0}\right)}$ is the agent $i$ 's discount factor from initial period to period $t$. Then $\lim _{t \rightarrow \infty} S_{i, t}\left(\frac{q_{t}}{p_{t}} a_{i, t}+f^{i} k_{i, t+1}\right)=0$.

(2) If the borrowing constraints of agent $i$ are not binding from $t_{0}$ to $t$ then $\frac{Q_{t}}{Q_{t_{0}}}=\frac{S_{i, t}}{S_{i, t_{0}}}$.

Proof. (1) Use the similar argument in Theorem 2.1 in Kamihigashi (2002) or see Le Van, Pham, and Vailakis (2014).

(2) See Le Van, Pham, and Vailakis (2014).

We now prove Proposition 8.

(1) We firstly suppose that $\limsup _{t \rightarrow \infty} \xi_{t}<\infty$. We always have

$$
\frac{r_{t+1}}{p_{t+1}}+1-\delta \leq \frac{Q_{t}}{Q_{t+1}}=\rho_{t+1}+1-\delta
$$

If $F^{\prime}(\infty) \geq \delta$ then for any $t, \rho_{t+1} \geq \frac{r_{t+1}}{p_{t+1}} \geq F^{\prime}(\infty) \geq \delta$. This implies $\sum_{t=0}^{\infty} \rho_{t+1}=+\infty$. From Proposition 6 , there is no bubble on the physical asset market.

If $F^{\prime}(\infty)<\delta$, by Lemma $1,\left(K_{t}\right)$ is bounded uniformly by some constant $K$, which implies that there $F^{\prime}\left(K_{t}\right) \geq F^{\prime}(K)$. For any $t, \rho_{t+1} \geq \frac{r_{t+1}}{p_{t+1}} \geq F^{\prime}(K)$. This implies $\sum_{t=0}^{\infty} \rho_{t+1}=+\infty$. From Proposition 6 , there is no bubble on the physical asset market.

We now suppose that $\limsup \xi_{t}=\infty$.

If $\delta=1$ then there is no physical bubble.

If $\delta<1$. Assume that physical bubble exists, $\lim _{t \rightarrow \infty}(1-\delta)^{t} Q_{t}=\bar{b}>0$ which implies that $\lim _{t \rightarrow \infty} Q_{t}=\frac{\bar{b}}{(1-\delta)^{t}}$. Since $\sum_{t=1}^{+\infty} Q_{t} \xi_{t}<\infty$, we obtain that $\sum_{t=1}^{+\infty} \frac{\xi_{t}}{(1-\delta)^{t}}<\infty$. However, it is easy to see that $\sum_{t=1}^{+\infty} \frac{\xi_{t}}{(1-\delta)^{t}}=\infty$ because $\limsup _{t \rightarrow \infty} \xi_{t}=\infty$, contradiction. Then there is no bubble on the physical asset market. 
(2) First, since $\liminf _{t \rightarrow \infty} \xi_{t}>0$ and $\sum_{t=1}^{+\infty} Q_{t} \xi_{t}<\infty$, we have $\sum_{t=1}^{+\infty} Q_{t}<\infty$.

According to Lemma 1, we have that $\left(K_{t}\right)$ is uniformly bounded. Hence, we obtain that $\lim _{T \rightarrow+\infty} Q_{T} k_{i, T+1}=0$ for any $i$, and

$$
\sum_{t=1}^{+\infty} F\left(K_{t}\right) Q_{t} \leq \sum_{t=1}^{+\infty} F(K) Q_{t}<\infty .
$$

We claim that we always have

$$
Q_{T} k_{i, T+1}=\left(1-\delta+\frac{r_{t+1}}{p_{t+1}}\right) Q_{T+1} k_{i, T+1} .
$$

Indeed, the claim is trivially true if $k_{i, T+1}=0$. If $k_{i, T+1}>0$ then $K_{T+1}>0$ and $Q_{T}=\left(1-\delta+\frac{r_{t+1}}{p_{t+1}}\right) Q_{T+1}($ see Lemma 7$)$.

For any agent $i$, we rewrite her/his budget constraint at date $t$ as follows

$$
Q_{t} c_{i, t}+Q_{t} k_{i, t+1}+Q_{t} \frac{q_{t}}{p_{t}} a_{i, t}=Q_{t}\left(\frac{r_{t}}{p_{t}}+1-\delta\right) k_{i, t}+Q_{t}\left(\frac{q_{t}}{p_{t}}+\xi_{t}\right) a_{i, t-1}+\theta^{i} \frac{\pi_{t}}{p_{t}} Q_{t} .
$$

By summing the budget constraints from $t$ equals 0 to $t$, and use (26), (82), we get

$$
\begin{aligned}
\sum_{t=0}^{T} Q_{t} c_{i, t}+Q_{T} k_{i, T+1}+Q_{T} \frac{q_{T}}{p_{T}} a_{i, T} & =\left(\frac{r_{0}}{p_{0}}+1-\delta\right) k_{i, 0}+\left(\frac{q_{0}}{p_{0}}+\xi_{0}\right) a_{i,-1}+\theta^{i} \sum_{t=0}^{T} \frac{\pi_{t}}{p_{t}} Q_{t} \\
& \leq\left(\frac{r_{0}}{p_{0}}+1-\delta\right) k_{i, 0}+\left(\frac{q_{0}}{p_{0}}+\xi_{0}\right) a_{i,-1}+\theta^{i} \sum_{t=0}^{T} F\left(K_{t}\right) Q_{t} \\
& <+\infty .
\end{aligned}
$$

According to the borrowing constraint of agent $i$ at date t, we have:

$$
0 \leq Q_{T} \frac{q_{T}}{p_{T}} a_{i, T}+f^{i}\left(1-\delta+\frac{r_{t+1}}{p_{t+1}}\right) Q_{T+1} k_{i, T+1}=Q_{T} \frac{q_{T}}{p_{T}} a_{i, T}+f^{i} Q_{T} k_{i, T+1}
$$

But

$$
f^{i} Q_{T} k_{i, T+1} \leq Q_{T} k_{i, T+1}
$$

We then obtain

$$
0 \leq Q_{T} \frac{q_{T}}{p_{T}} a_{i, T}+Q_{T} k_{i, T+1}
$$

Therefore, $\sum_{t=0}^{\infty} Q_{t} c_{i, t}<+\infty$, and then $\lim _{T \rightarrow+\infty} Q_{T} k_{i, T+1}+Q_{T} \frac{q_{T}}{p_{T}} a_{i, T}$ exists. Since $\lim _{T \rightarrow+\infty} Q_{T} k_{i, T+1}=0$, we have $\lim _{T \rightarrow+\infty} Q_{T} \frac{q_{T}}{p_{T}} a_{i, T}$ exists. If there exists a bubble then $\lim _{T \rightarrow+\infty} a_{i, T}$ exists. This property holds for any $i$. As a consequence, there exists $i$ such that $\lim _{T \rightarrow+\infty} a_{i, T}>0$. For this agent, there exists $T$ such that the borrowing constraints will not bind for $t \geq T$. We have from Lemma 20 that $\frac{Q_{t}}{Q_{T}}=\frac{S_{i, t}}{S_{i_{T}}}$, for any $t \geq T$. We then have, by using Lemma 20

$$
\lim _{t \rightarrow+\infty} Q_{t} \frac{q_{t}}{p_{t}} a_{i, t}=\frac{Q_{T}}{S_{i, T}} \lim _{t \rightarrow+\infty} S_{i, t} \frac{q_{t}}{p_{t}} a_{i, t}=0
$$

which is a contradiction. We conclude that there is no bubble on the financial asset market. 
Proof for Section 6.1. It is easy to see that all market clearing conditions are satisfied.

Since $r_{t}=a_{t}$, the optimality of the production plan is satisfied.

We will verify the optimality of $\left(c_{i}, k_{i}, a_{i}\right)$.

Let us consider FOCs

$$
\begin{aligned}
\beta_{i}^{t} u_{i}^{\prime}\left(c_{i, t}\right) & =\mu_{i, t} \\
\frac{1}{r_{t+1}+1-\delta} & =\frac{\beta_{i} u_{i}^{\prime}\left(c_{i, t+1}\right)}{u_{i}^{\prime}\left(c_{i, t}\right)}+\sigma_{i, t} \\
\frac{q_{t}}{q_{t+1}+\xi_{t+1}} & =\frac{\beta_{i} u_{i}^{\prime}\left(c_{i, t+1}\right)}{u_{i}^{\prime}\left(c_{i, t}\right)}+\nu_{i, t}
\end{aligned}
$$

Note that $\sigma_{i, t}, \nu_{i, t} \geq 0$ and $\sigma_{i, t} k_{i, t+1}=0$ and $\nu_{i, t} a_{i, t}=0$.

We rewrite as follows: for each $i$,

$$
\begin{aligned}
\frac{1}{r_{t+1}+1-\delta} & =\frac{\beta c_{i, t}}{c_{i, t+1}}+\sigma_{i, t} \\
\frac{q_{t}}{q_{t+1}+\xi_{t+1}} & =\frac{\beta c_{i, t}}{c_{i, t+1}}+\nu_{i, t}
\end{aligned}
$$

We can compute that

$$
\begin{aligned}
\frac{\beta u^{\prime}\left(c_{F, 2 t+1}\right)}{u^{\prime}\left(c_{F, 2 t}\right)} & =\beta\left(1-\delta+r_{2 t}\right) \frac{\pi_{2 t}}{\pi_{2 t+1}} \\
\left(r_{2 t+1}+1-\delta\right) \frac{\beta c_{F, 2 t}}{c_{F, 2 t+1}} & =\beta^{2}\left(1-\delta+r_{2 t}\right)\left(1-\delta+r_{2 t+1}\right) \frac{\pi_{2 t}}{\pi_{2 t+1}} \\
\frac{\beta u^{\prime}\left(c_{H, 2 t}\right)}{u^{\prime}\left(c_{H, 2 t-1}\right)} & =\beta\left(1-\delta+r_{2 t-1}\right) \frac{\pi_{2 t-1}}{\pi_{2 t}} \\
\left(r_{2 t}+1-\delta\right) \frac{\beta c_{H, 2 t-1}}{c_{H, 2 t}} & =\beta^{2}\left(1-\delta+r_{2 t-1}\right)\left(1-\delta+r_{2 t}\right) \frac{\pi_{2 t-1}}{\pi_{2 t}} .
\end{aligned}
$$

Since $r_{t}=a_{t}$ such that $\beta\left(1-\delta+a_{t}\right) \leq 1$, all FOCs are satisfied.

We now check transversality conditions

$$
\lim _{t \rightarrow \infty} \beta_{i}^{t} u_{i}^{\prime}\left(c_{i, t}\right) k_{i, t+1}=\lim _{t \rightarrow \infty} \beta_{i}^{t} u_{i}^{\prime}\left(c_{i, t}\right) q_{t} a_{i, t}=0 .
$$

It is clear that

$$
\beta_{H}^{2 t-1} u_{H}^{\prime}\left(c_{H, 2 t-1}\right) k_{H, 2 t}=0=\lim _{t \rightarrow \infty} \beta_{F}^{2 t} u_{F}^{\prime}\left(c_{F, 2 t}\right) q_{2 t} a_{F, 2 t} .
$$

We also have

$$
\begin{aligned}
\beta^{2 t} u^{\prime}\left(c_{H, 2 t}\right) & =u^{\prime}\left(c_{H, 0}\right) \frac{\beta u^{\prime}\left(c_{H, 2 t}\right)}{u^{\prime}\left(c_{H, 2 t-1}\right)} \frac{\beta u^{\prime}\left(c_{H, 2 t-1}\right)}{u^{\prime}\left(c_{H, 2 t-2}\right)} \cdots \frac{\beta u^{\prime}\left(c_{H, 2}\right)}{u^{\prime}\left(c_{H, 1}\right)} \frac{\beta u^{\prime}\left(c_{H, 1}\right)}{u^{\prime}\left(c_{H, 0}\right)} \\
& =u^{\prime}\left(c_{H, 0}\right) \beta\left(1-\delta+r_{2 t-1}\right) \frac{\pi_{2 t-1}}{\pi_{2 t}} \frac{1}{1-\delta+r_{2 t-1}} \cdots \beta\left(1-\delta+r_{1}\right) \frac{\pi_{1}}{\pi_{2}} \frac{1}{1-\delta+r_{1}} \\
& =u^{\prime}\left(c_{H, 0}\right) \beta^{t} \frac{\pi_{2 t-1}}{\pi_{2 t}} \cdots \frac{\pi_{1}}{\pi_{2}}=u^{\prime}\left(c_{H, 0}\right) \beta^{t} .
\end{aligned}
$$




$$
\begin{aligned}
\beta^{2 t+1} u^{\prime}\left(c_{F, 2 t+1}\right) & =u^{\prime}\left(c_{F, 1}\right) \frac{\beta u^{\prime}\left(c_{F, 2 t+1}\right)}{u^{\prime}\left(c_{F, 2 t}\right)} \frac{\beta u^{\prime}\left(c_{F, 2 t}\right)}{u^{\prime}\left(c_{H, 2 t-1}\right)} \cdots \frac{\beta u^{\prime}\left(c_{F, 3}\right)}{u^{\prime}\left(c_{F, 2}\right)} \frac{\beta u^{\prime}\left(c_{F, 2}\right)}{u^{\prime}\left(c_{F, 1}\right)} \\
& =\beta u^{\prime}\left(c_{F, 1}\right) \beta\left(1-\delta+r_{2 t}\right) \frac{\pi_{2 t}}{\pi_{2 t+1}} \frac{1}{1-\delta+r_{2 t}} \cdots \beta\left(1-\delta+r_{2}\right) \frac{\pi_{2}}{\pi_{3}} \frac{1}{1-\delta+r_{2}} \\
& =\beta u^{\prime}\left(c_{F, 1}\right) \beta^{t} \frac{\pi_{2 t}}{\pi_{2 t+1}} \cdots \frac{\pi_{2}}{\pi_{3}}=\beta^{t+1} u^{\prime}\left(c_{F, 1}\right) .
\end{aligned}
$$

Combining these equalities and (60), we obtain transversality conditions.

\section{References}

Alvarez F. and U.J. Jermann, Efficiency, equilibrium, and asset pricing with risk of default, Econometrica 70, 775-798 (2014).

Araujo A., Pascoa M.R., and Torres-Martinez J.P., Collateral avoids Ponzi schemes in incomplete markets, Econometrica 70, p. 1613-1638, 2002.

Becker R., S. Bosi S., Le Van C., and Seegmuller T., On existence and bubbles of Ramsey equilibrium with borrowing constraints, Economic Theory, forthcoming, 2014.

Becker R. A. and Boyd III, J. H. , and Foias, C., The existence of Ramsey equilibrium, Econometrica 59, p. 441-460, 1991.

Becker R.A., Dubey R.S., and Mitra T., On Ramsey equilibrium: capital ownership pattern and inefficiency, Economic Theory 55, p. 565-600, 2014.

Becker R. and T. Mitra, Efficient Ramsey equilibria, Macroeconomic Dynamics 16, 18-32 (2012).

Becker B., Gertler, M, and Gilchrist, S., The Financial accelerator in a quan- titative business cycle framework, Handbook of Macroeconomics, volume 1, chapter 21, p. 1341-1393. Elsevier, 1999.

Bloise G. and P. Reichlin, Asset prices, debt constraints and inefficiency, Journal of Economic Theory 146, 1520-1546 (2011).

Bosi, S., Le Van, C., and Pham, N. S., Intertemporal equilibrium with production: bubbles and efficiency, CES working paper, 2014.

Brunnermeier M, Eisenback T., and Sannikov Y., Macroeconomics with Financial Frictions: A Survey. NBER Working Papers 18102, National Bureau of Economic Research, Inc, May 2012.

Brunnermeier M, and Sannikov Y., A macroeconomic model with a financial sector. American Economic Review 104 (2), p. 379-421, 2014. 
Cass D. and M.E. Yaari, Present values playing the role of efficiency prices in the one-good growth model, Review of Economic Studies 38, 331-39 (1971).

Cass D., On capital overaccumulation in the aggregative, neoclassical model of economic growth: A complete characterization, Journal of Economic Theory 4, 200$223(1972)$.

Christiano L., Motto R., and Rostagno M., Financial factors in economic fluctuations, mimeo, 2010.

Davila J., J.H. Hong, P. Krusell and J.-V. Ríos-Rull, Constrained efficiency in the neoclassical growth model with uninsurable idiosyncratic shocks, Econometrica 80, 2431-2467 (2012).

Gabaix, X., The granular origins of aggregate fluctuations. Econometrica, 79(3), p. 733-772, May 2011.

Geanakoplos J., and Zame W., Collateral and the enforcement of intertemporal contracts. Working paper, 2002.

Gertler M. and Kiyotaki N., Financial Intermediation and Credit Policy in Business Cycle Analysis. Handbook of monetary economics, vol 3. Elsevier B.V, 2010.

Gilles, C., and LeRoy S., Bubbles and charges, International Economic Review 33, 323-339 (1992).

Guvenen F., Macroeconomics with heterogeneity: a practical guide.. NBER Working Paper No. 17622, 2012.

Huang K. X. D. and Werner J., Asset price bubbles in Arrow-Debreu and sequential equilibrium, Economic Theory 15, 253-278(2000).

Kamihigashi T., A simple proof of the necessity of the transversality condition, Economic Theory 20, 427-433 (2002).

Kehoe T. and D. Levine, Debt Constrained Asset Markets, Review of Economic Studies 60, 865-888 (1993).

Kiyotaki N. and Moore J., Credit cycles. Journal of Political Economy, 105(2), p. 211-248, 1997.

Kocherlakota, N. R., Bubbles and constraints on debt accumulation, Journal of Economic Theory, 57, 245 - 256 (1992).

Kubler F., and Schmedders K., Stationary equilibria in Asset-Pricing Models with Incomplete Markets and Collateral, Econometrica, vol. 71, No. 6, pp. 1767-1793, 2003.

Le Van C., Pham N.S., and Vailakis Y., Financial asset bubble with heterogeneous agents and endogenous borrowing constraints, Working paper, 2014. 
Levine D., Infinite horizon equilibrium with incomplete markets, Journal of Mathematical Economics, vol. 18(4), pages 357-376, 1989

Levine D. and Zame W., Debt constraints and equilibrium in infinite horizon economies with incomplete markets, Journal of Mathematical Economics, vol. 26(1), pages 103-131, 1996.

Magill M. and Quinzii M., Infinite Horizon Incomplete Markets, Econometrica, vol. 62(4), pages 853-80, 1994.

Magill M. and Quinzii M., Incomplete markets over an infinite horizon: Long-lived securities and speculative bubbles, Journal of Mathematical Economics, vol. 26(1), pages 133-170, 1996

Magill M. and Quinzii M., Incomplete markets, volume 2, infinite horizon economies, Edward Elgar Publishing Company, 2008.

Malinvaud E., Capital accumulation and efficient allocation of resources. Econometrica, 21(2), p. 233-268, 1953.

Matsuyama K., Aggregate implications of credit market imperfections. In NBER Macroeconomics Annual 2007, Volume 22, NBER Chapters, p. 1-60, 2007.

Mitra T. and D. Ray, On the Phelps-Koopmans theorem, Journal of Economic Theory 147, 833-849 (2012).

Pham, N-S., Collateral monetary equilibrium with liquidity constraints in an infinite horizon economy. Documents de travail du Centre d'Economie de la Sorbonne, Jul 2013.

Santos M. S. and Woodford M. Rational asset pricing bubbles, Econometrica, 65, 19-57 (1997).

Scheinkman J. and Weiss L., Borrowing Constraints and Aggregate Economic Activity. Econometrica, 54(1), p. 23-45, January 1986. 